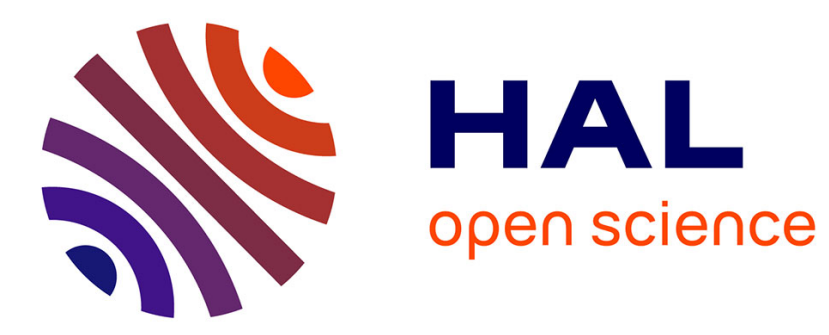

\title{
Technical note: application of ?-QSS to the numerical integration of kinetic equations in tropospheric chemistry
}

\author{
Franklin Liu, E. Schaller, D. R. Mott
}

\section{- To cite this version:}

Franklin Liu, E. Schaller, D. R. Mott. Technical note: application of ?-QSS to the numerical integration of kinetic equations in tropospheric chemistry. Atmospheric Chemistry and Physics Discussions, 2005, 5 (4), pp.6215-6262. hal-00301706

\section{HAL Id: hal-00301706 https://hal.science/hal-00301706}

Submitted on 18 Aug 2005

HAL is a multi-disciplinary open access archive for the deposit and dissemination of scientific research documents, whether they are published or not. The documents may come from teaching and research institutions in France or abroad, or from public or private research centers.
L'archive ouverte pluridisciplinaire HAL, est destinée au dépôt et à la diffusion de documents scientifiques de niveau recherche, publiés ou non, émanant des établissements d'enseignement et de recherche français ou étrangers, des laboratoires publics ou privés. 
Numerical integration of troposphere photochemistry mechanism

\section{Technical note: application of $\alpha$-QSS to the numerical integration of kinetic equations in tropospheric chemistry}

F. Liu ${ }^{1}$, E. Schaller ${ }^{1}$, and D. R. Mott ${ }^{2}$

${ }^{1}$ Department of Environmental Meteorology, BTU Cottbus, Germany

${ }^{2}$ Laboratory for Computational Physics and Fluid Dynamics, Naval Research Laboratory, Washington, DC 20375-5320, USA

Received: 9 May 2005 - Accepted: 6 July 2005 - Published: 18 August 2005

Correspondence to: F. Liu (Ifeng @tu-cottbus.de)

(C) 2005 Author(s). This work is licensed under a Creative Commons License.
F. Liu et al.

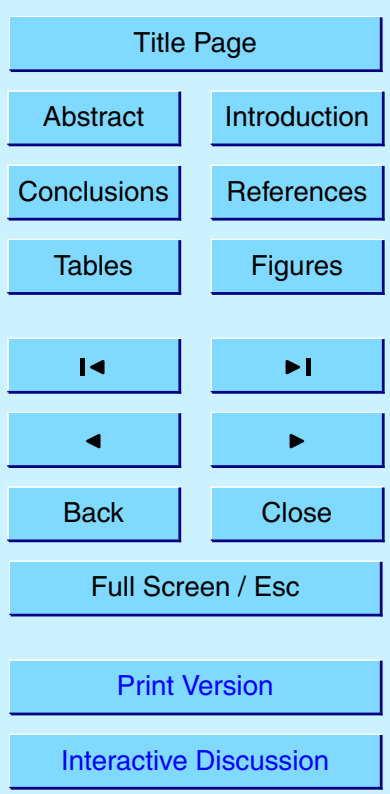




\section{Abstract}

A major task in many applications of atmospheric chemistry transport problems is the numerical integration of stiff systems of Ordinary Differential Equations (ODEs) describing the chemical transformations. A faster solver that is easier to couple to the

other physics in the problem is still needed. The integration method, $\alpha$-QSS, corresponding to the solver CHEMEQ2 aims at meeting the demands of a process-split, reacting-flow simulation (Mott 2000; Mott and Oran, 2001). However, this integrator has yet to be applied to the numerical integration of kinetic equations in tropospheric chemistry. A zero-dimensional (box) model is developed to test how well CHEMEQ2 works on the tropospheric chemistry equations. This paper presents the testing results. The reference chemical mechanisms herein used are Regional Atmospheric Chemistry Mechanism (RACM) (Stockwell et al., 1997) and its secondary lumped successor Regional Lumped Atmospheric Chemical Scheme (ReLACS) (Crassier et al., 2000). The box model is forced and initialized by the DRY scenarios of Protocol Ver.2 developed by EUROTRAC (Poppe et al., 2001). The accuracy of CHEMEQ2 is evaluated by comparing the results to solutions obtained with VODE. This comparison is made with parameters of the error tolerance, relative difference with respect to VODE scheme, trade off between accuracy and efficiency, global time step for integration etc. The study based on the comparison concludes that the single-point $\alpha$-QSS approach is fast and moderately accurate as well as easy to couple to reacting flow simulation models, which makes CHEMEQ2 one of the best candidates for three-dimensional atmospheric Chemistry Transport Modelling (CTM) studies. In addition the RACM mechanism may be replaced by ReLACS mechanism for tropospheric chemistry transport modelling. The testing results also imply that the accuracy for chemistry numerical choice for testing numerical ODE solvers or for evaluation of mechanisms because current tropospheric chemistry mechanisms are mainly designed for troposphere ozone prediction.

ACPD

$5,6215-6262,2005$

Numerical integration of troposphere photochemistry mechanism

F. Liu et al.

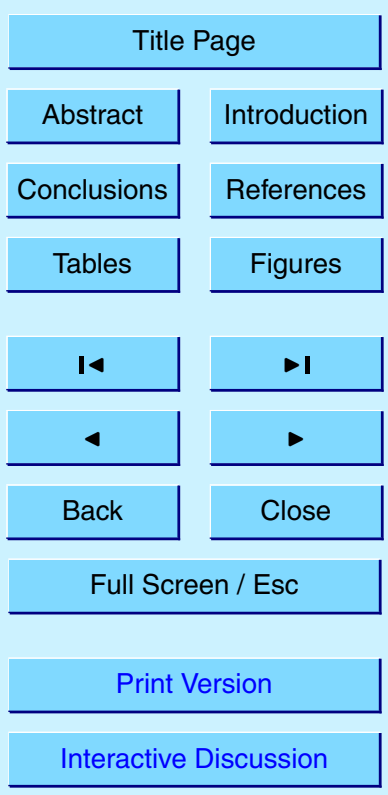




\section{Introduction}

For the improvement of understanding the transport and fate of trace gases and pollutants in the atmosphere, comprehensive atmospheric Chemistry and Transport Models (CTMs) have been developed. The operator splitting approach is very often used in the 5 numerical solution of these equations. A major task is then the numerical integration of the stiff Ordinary Differential Equation (ODE) system describing the chemical transformation in the atmosphere, which leads to two important aspects that must be considered: efficiency and accuracy. Efficiency requires a relatively fast chemical solver. Because the corresponding ODEs are stiff, their solution normally requires at least $50 \%$ of the total CPU time. In studies on chemical integrations alone and in the development of atmospheric chemistry mechanisms, some standard stiff ODEs solvers have been intensively used, and they continue to be refined and developed (Gear, 1971; Hindmarsh, 1983; Hindmarsh and Norsett, 1988; Brown et al., 1989; Hairer and Wanner, 1991; Radhakrishnan and Hindmarsh, 1993). These solvers designed for chemistry stand-alone solutions of ODEs are very accurate but computationally more expensive per time step due to the use of the solution from several previous time steps.

In a CTM chemical transformations are only one of several processes, including in addition transport, turbulent diffusion, wet scavenging etc. The total change of the concentration of species $i, n_{i}$, can be derived from the mass conservative principle, i.e.

${ }_{20} \frac{\partial n_{i}}{\partial t}=-\frac{\partial}{x_{k}}\left(n_{i} v_{k}\right)+\frac{\partial}{\partial x_{k}}\left(-\overline{n_{i}^{\prime} v_{k}^{\prime}}\right)+E_{i}-S_{i}+\left(P_{i}-L_{i} n_{i}\right)$

using the operator (process) splitting approach. The basic idea of operator splitting is to calculate the effects of each individual process separately for a chosen global time step $\Delta t_{g}$, and then combine the results according to Eq. (1). The integration of the ODEs representing the chemical transformation during $\Delta t_{g}$, is a local initial value problem at
ACPD

$5,6215-6262,2005$

Numerical integration of troposphere photochemistry mechanism

F. Liu et al.

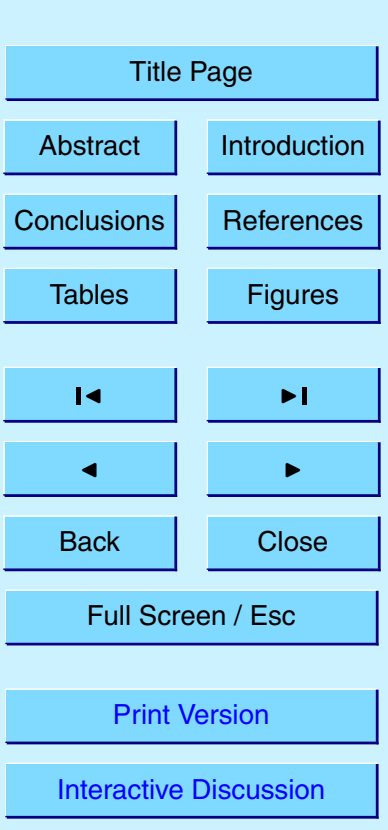


is heavily dependent on the timescale of the chemistry system, and varies generally during the course of a simulation.

A faster and easier-coupling ODE integrator is one of the most important parts in a three dimensional CTM because the high demand of CPU time for chemical inte5 gration. Easier-coupling means that the integrator works well within the framework of a process-split reacting flow algorithm. For this purpose much faster but moderately accurate methods which are generally different from those designed for chemistry stand-alone solutions of ODE systems have been developed. The trade-offs between accuracy and efficiency must be considered for specific problems which have different 10 requirements of accuracy (Young and Boris, 1977; Oran and Boris, 1987, 2000). Such faster algorithms are in use in atmospheric models. Comparisons between different solvers have been performed (Shieh et al, 1988; Hertel et al., 1993; Saylor and Ford, 1995; Verwer and Loon, 1995; Sandu et al., 1995, 1996; Lorenzini and Passoni, 1999). Some standard solvers show comparable efficiency and accuracy for different chemical schemes (Sandu et al., 1996). The accuracy level should be considered in relation to the global accuracy requirement of the CTM. Calculations of atmospheric dynamics are seldom more accurate than a few percent. Thus, any requirement to the chemical integrator to calculate the species concentrations more accurate than a few tenths of a percent is usually excessive. Therefore the chemical integrator may be of relatively 20 low-order. Furthermore, since the integrator must solve multiple initial value problems, it is advantageous to use a single-point method that requires information only from the current time level to calculate the concentration at the end of each global time step.

As the first step to apply an efficient chemical integrator to a tropospheric CTM, a box model is developed and implemented. This paper presents the results of applying the ODE integration algorithm, $\alpha$-QSS (Mott, et al., 2000; Mott and Oran, 2001), to tropospheric gas-phase chemistry within the box model. The solver CHEMEQ2 based on $\alpha$-QSS was developed specifically to meet the above demands of a process-split, reacting-flow simulation.

This paper is organized as follows. Section 2 describes tropospheric chemistry

ACPD

5, 6215-6262, 2005

Numerical integration of troposphere photochemistry mechanism

F. Liu et al.

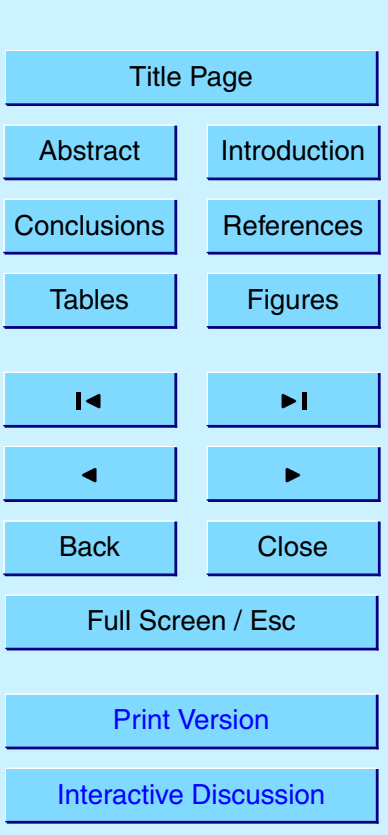

EGU 
mechanisms and scenarios used for testing CHEMEQ2. In Sect. 3 we describe the $\alpha$-QSS algorithm as implemented in CHEMEQ2. Section 4 includes testing results and Sect. 5 gives an analysis in respect to the accuracy and efficiency of the tested solver. The final Sect. 6 collects some general remarks and final conclusions.

\section{2. Description of the applied chemical mechanisms RACM and ReLACS}

Gas-phase reaction mechanisms consist of an inorganic and an organic parts, especially the inorganic chemistry in the atmosphere is well understood. The complexity lies in the representation of the organic part of the mechanism. Thousands of chemical reactions and products are found in the lower atmosphere. Explicit, highly detailed chem10 ical mechanisms such as Master Chemical Mechanism (MCM) developed by Jenkin et al. (1997) and Derwent et al. (1998) attempt to treat all chemical species and reactions individually. However, the difficulties with explicit mechanisms are twofold. Firstly, it is difficulty to identify the reactants, intermediates, products, and rate constants for reactions. Secondly, it is computationally complex for integrating the large number of 15 equations. Therefore, most photochemical models use a lumped chemical mechanism or reduced mechanism, within which a surrogate species is created to present a group of individual organic species. The major approaches for lumping are either Lumped Structure (LS) or Lumped Molecule (LM) approach. Over the last few decades a series of lumped mechanisms and their successors have been proposed for the chemistry of

the atmosphere, i.e. the Acid Deposition and Oxidant Mode II mechanism (ADOM-II) (Lurmann et al., 1986), the Carbon Bon Mechanism IV (CB-IV) (Gery et al., 1989), the Co-operative Programme for Monitoring and Evaluation of the Long-Range Transmission of Air Pollutants in Europe (EMEP) (Simpson et al., 1993, 1997), the second generation Regional Acid Deposition Model Mechanism (RADM2) (Stockwell et al., 1990),
Euro-RADM (Stockwell and Kley, 1994), Regional Atmospheric Chemistry Mechanism (RACM) (Stockwell et al., 1997) and the Regional Lumped Atmospheric Chemical Scheme (ReLACS) (Crassier et al., 2000). Intercomparisons of some mechanisms
ACPD

$5,6215-6262,2005$

Numerical integration of troposphere photochemistry mechanism

F. Liu et al.

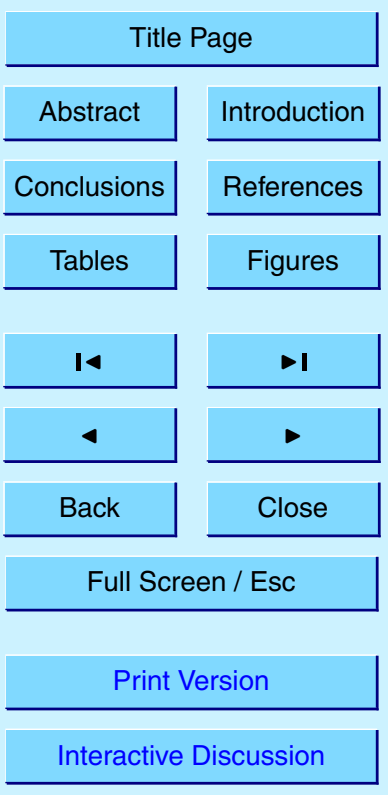


were carried out by Poppe et al. (1996), Kuhn et al. (1998), Stockwell et al. (1998), Jimenez et al. (2003) and Gross and Stockwell (2003). Since the publication of the earlier studies many chemistry data including rate constant and kinetic data have been revised and updated according to new laboratory work. The RACM mechanism is a 5 substantially revised version of RADM2 mechanism from the more recent laboratory measurements. Thus, the RACM mechanism must be considered to be superior to the RADM2 mechanism although the RADM2 has been used in many CTMs to predict concentrations of oxidants and other air pollutants (Gross and Stockwell, 2003). The RACM mechanism was developed to simulate tropospheric chemistry from the surface

10 to the upper troposphere in remote to polluted urban conditions. It includes 77 species and 237 reactions (see Appendix). Although the RACM mechanism is much smaller than MCM it is a still too large and numerically expensive for long-term simulation in a CTM. As a simplified RACM the ReLACS is a relatively highly lumped mechanism. The ReLACS mechanism is derived from a new reactivity weighting approach and almost keeps all information in RACM (Crassier et al., 2000). The ReLACS reduces prognostic species and reactions from 67 and 237 in RACM to 37 and 128 (see Appendix). This paper aims at the evaluation of the fast solver CHEMEQ2 with RACM and lumped ReLACS mechanisms for use in a CTM.

\section{Introduction to the $\alpha$-QSS method}

20 The concentration changes with time due to chemical reactions for a set of $N$ chemical species are described by a system of $N$ ordinary differential equations (ODEs),

$\frac{d n_{i}}{d t}=P_{i}-L_{i} n_{i} \quad 1 \leq i \leq N$

where $i$ is the species index, $n_{i}$ is the number density of $i$ th species, and $P_{i}$ and $L_{i} n_{i}$ are the production and loss terms, respectively. For tropospheric chemistry this ODE system is nonlinear, highly coupled, and very stiff. If $P$ and $L$ are constant, then Eq. (2)

ACPD

$5,6215-6262,2005$

Numerical integration of troposphere photochemistry mechanism

F. Liu et al.

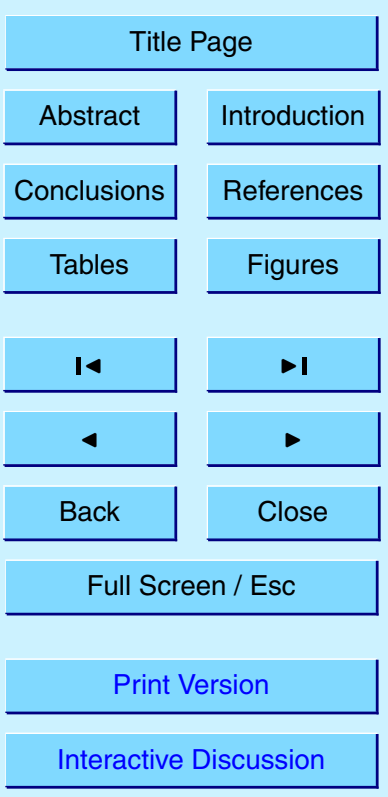

EGU 
$n_{i}(t)=n_{i 0} e^{(-t / \tau)}+P_{i} \tau\left(1-e^{(-t / \tau)}\right)$

where $\tau=1 / L$ is the chemical time scale. Quasi-Steady-State (QSS) methods are based on the solution given by Eq. (3) (Verwer and van Loon, 1994; Verwer and Simpson, 1995; Jay et al., 1997; Radhakrishnan and Pratt, 1988). They differ in how they incorporate the time dependence of $P_{i}$ and $L_{i}$. They must not be confused with "steadystate" methods, in which the net chemical source term for some species is assumed to be zero. In this work and in the literature cited above, QSS refers to using Eq. (3) as the starting point for deriving an ODE integrator that retains all the timescale information present in the chemical mechanism.

Next, we introduce a parameter $\alpha$ defined as

$\alpha=\alpha(\Delta t / \tau)=\frac{1-\tau / \Delta t\left(1-e^{-\Delta t / \tau}\right)}{1-e^{-\Delta t / \tau}}$

and rearrange Eq. (3) to

$n(\Delta t)=n_{0}+\frac{\Delta t\left(P-n_{0} / \tau\right)}{1+\alpha \Delta t / \tau}$

15 The parameter $\alpha$ is a function of $\Delta t / \tau$, as shown in Fig. 1. The $n / \tau$ has to be nonnegative, so only values of $\Delta t / \tau \geq 0$ need to be considered. Note that if $\tau \ll \Delta t$, the exponential term in Eq. (3) decays rapidly, and steady-state is approached quickly. In this case, for initial conditions far from steady-state, the loss term dominates the initial rate of evolution but then rapidly drops in magnitude as $n$ is depleted and steadystate is approached. The $\Delta t / \tau \rightarrow \infty$ limit for an infinitely fast ODE corresponds to $\alpha \rightarrow 1$. Conversely, when $\tau \gg \Delta t$, then the exponential term in Eq. (3) slowly decays. The $\Delta t / \tau \rightarrow 0$ limit for an infinitely slow ODE corresponds to $\alpha \rightarrow \frac{1}{2}$. If the loss term is

Numerical integration of troposphere photochemistry mechanism

F. Liu et al.

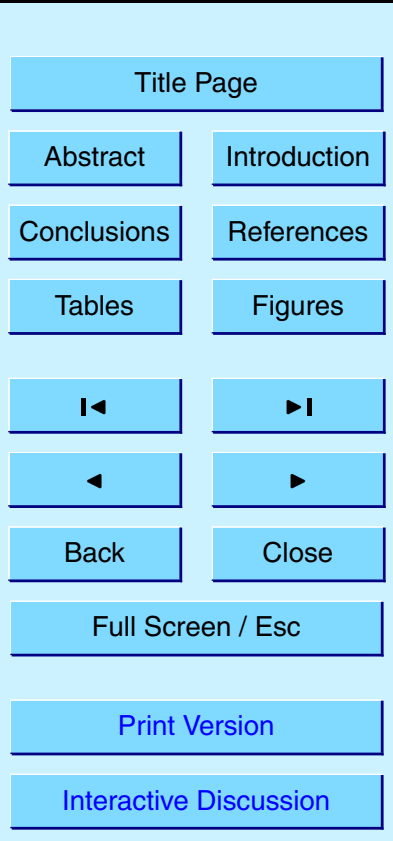

EGU 
identically equal to zero because $L_{i}=0$, then the solution for $\mathrm{n}$ is linear in time and the exact solution does not include the exponential term.

Given the demands of a reacting-flow application, $\alpha$-QSS uses a predictor-corrector implementation. The predictor $n_{p}$ takes the form

${ }_{5} n_{p}=n_{0}+\frac{\Delta t\left(P_{0}-n_{0} / \tau_{0}\right)}{1+\alpha_{0} \Delta t / \tau_{0}}$

and the corrector $n_{C}$ is given by

$n_{c}=n_{0}+\frac{\Delta t\left(P^{*}-n_{0} / \tau^{*}\right)}{1+\alpha^{*} \Delta t / \tau^{*}}$

The index 0 indicates initial values, of $P, \tau, \alpha$ and $n$. The averaged variables $P^{\star}, \tau^{\star}$, and $\alpha^{*}$ are based on both the initial and the predicted values according to

${ }_{10} \frac{1}{\tau^{*}}=\frac{1}{2}\left(\frac{1}{\tau_{0}}+\frac{1}{\tau_{p}}\right)$

$\alpha^{*}=\alpha\left(\Delta t / \tau^{*}\right)$, and

$P^{*}=\alpha^{*} P_{p}+\left(1-\alpha^{*}\right) P_{0}$

where the index $P$ indicates the 'predicted' values. The corrector step can be repeated using the previous corrector result as the new predicted value. Predictor-corrector methods of this type are single-point methods because information from only one a single time level is needed to initiate calculation of the solution at the next time level. The $\alpha$-QSS method differs from previous QSS methods in its algebraic form (i.e., the use of the parameter $\alpha$ ), the choice of $\alpha$-weighted average for $P$, and the implementation as a predictor-corrector method. Previous methods calculate average values for

$20 \quad P$ as arithmetic mean of $P_{0}$ and $P_{P}$ (Radhakrishnan and Pratt, 1988; Verwer and Loon, 1994; Verwer and Simpson, 1995).

ACPD

5, 6215-6262, 2005

Numerical integration of troposphere photochemistry mechanism

F. Liu et al.

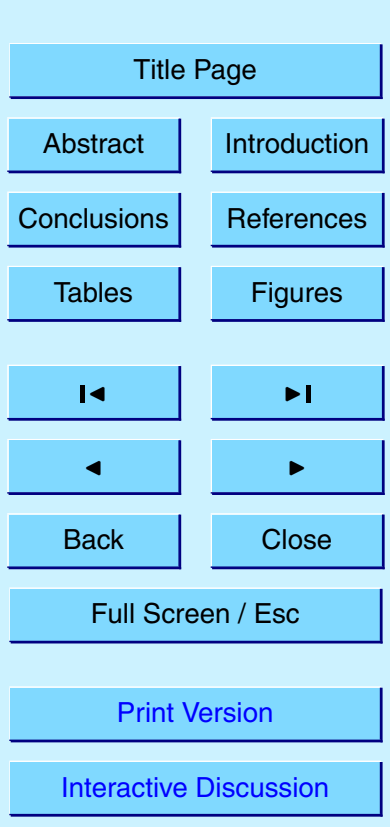

EGU 
The integrator CHEMEQ2 used in the current study is based on the $\alpha$-QSS method (Mott, 1999; Mott and Oran, 2001). The accuracy of the integration is determined by the number of corrector iterations, $N c$, and the time step, $\Delta t$. The timestep is calculated in the original way by CHEMEQ (Mott and Oran, 2001). The initially predicted values and 5 final corrected values for species $i$ are tested to see if they satisfy

$$
\frac{\left\|n_{i c}-n_{i p}\right\|}{n_{i c}} \leq \varepsilon
$$

for an user specified accuracy parameter. The parameter $\varepsilon$ is defined as the predictorcorrector error tolerance. If Eq. (11) is not satisfied, the step is repeated with a smaller timestep. The parameter $\varepsilon$ can be considered as the target relative error tolerance. In

10 the current study, values of $\varepsilon$ are taken as $0.10,0.05$, and 0.01 , and unless otherwise specified, $N_{c}=1$.

\section{Testing results}

The comparison in this study is based upon the "Scenarios for Modelling of Multi-Phase Tropospheric Chemistry Version 2" (Poppe et al., 2001), which is available under: 15 http://www.fz-juelich.de/icg/icg-ii/ALLGEMEIN/cmdform.all.html. Six scenarios are defined encompassing the remote planetary boundary layer over the continent (LAND) and the ocean (MARINE), the free troposphere (FREE), and three cases with varying burdens of anthropogenic and biogenic emissions (PLUME, URBAN, and URBAN/BIO) (Table 1). For our study only DRY Scenarios are used for the testing because the fo-
ACPD

$5,6215-6262,2005$

Numerical integration of troposphere photochemistry mechanism

F. Liu et al.

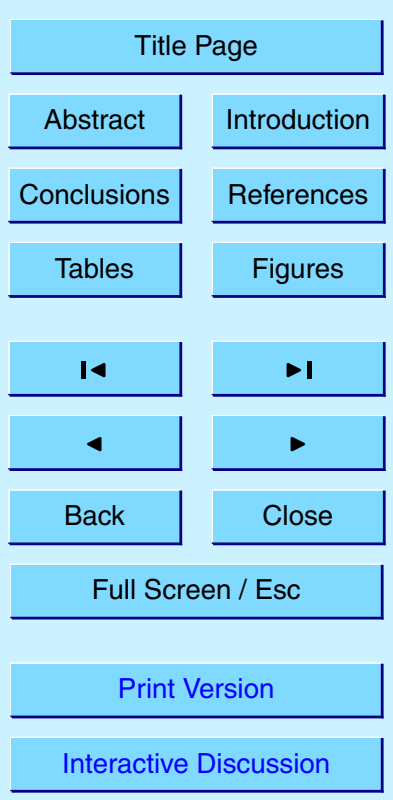


This test focuses on CHEMEQ2's ability to integrate ODEs efficiently at moderate accuracy on the one hand. The test examines the mechanism ReLACS's ability to predict ozone concentrations on the other. For this testing $\varepsilon=0.01$ and $N c=1$ are fixed. In accordance with above purposes three modes (see Table 2) are implemented 5 separately.

The simulations for $\mathrm{O}_{3}$, and ozone precursors $\mathrm{NO}, \mathrm{NO}_{2}, \mathrm{HO}$, organic peroxy radicals $\left(\mathrm{RO}_{2}\right)$ and peroxyacetyl nitrate (PAN) with the LAND, FREE, and PLUME cases are illustrated in Figs. 2 and 3. Since the RACM and ReLACS were designed and validated primarily for predicting ozone, agreement in ozone for the two mechanisms is expected 10 even for the PLUME case with emissions. It can be seen in Fig. 4 that the differences of $\mathrm{O}_{3}$ simulations for the three modes are increasing with simulation time but the maximum difference is less than $4 \mathrm{ppb}(\mathrm{v})$. This is accurate enough considering the error tolerance of the $\mathrm{O}_{3}$ observations. Despite this agreement in ozone, relatively significant differences for ozone precursors are seen between the two mechanisms. The difference in $\mathrm{NO}_{2}$ between the two mechanisms is significantly high, but still less than 0.3 ppbv over 5 days, which might be caused by the over prediction of $\mathrm{NO}_{2}$ by ReLACS during night. The study of Crassier et al. (2000) provides a detailed comparison of the mechanisms RACM and ReLACS.

The excellent agreement between the results from the different modes indicates that 20 (1) the solver CHEMEQ2 is suitable for the numerical solution of the troposphere chemical balance equations, and (2) the mechanism ReLACS may replace RACM for ozone prediction.

In order to further investigate CHEMEQ2's sensitivity to the source strengths of NO and isoprene we use Mode B to simulate the URBAN and URBAN/BIO cases. In the URBAN case the emission strength of NO is as high as 5 times that of $Q_{0}$ in PLUME. The initial concentrations for $\mathrm{NO}, \mathrm{NO}_{2}$, and $\mathrm{CO}$ are changed (Poppe et al., 2001) and VOC emissions remain unchanged (see Table 3). This case is designed for polluted urban area with varying burdens of anthropogenic emissions. It can be seen in Fig. 5 that the simulations give high $\mathrm{NO}_{2}$ concentrations over 5 days that lead to

ACPD

$5,6215-6262,2005$

Numerical integration of troposphere photochemistry mechanism

F. Liu et al.

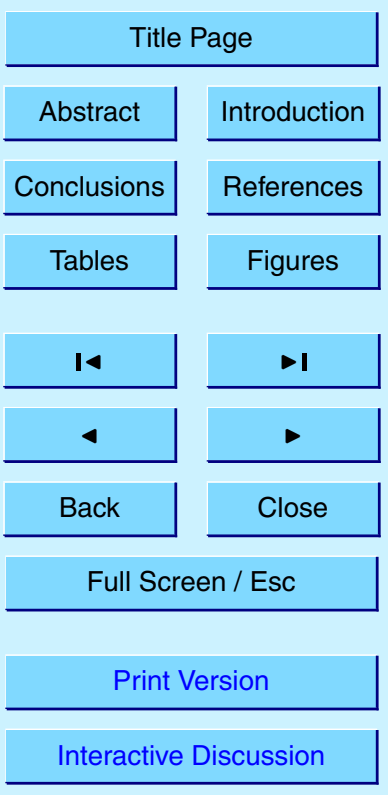

EGU 
very low production of ozone. Ozone production initially increases with the reduction of the emission strength of NO. The maximum ozone concentration reaches $178 \mathrm{ppb}(\mathrm{v})$ when the emission strength of NO is approximately 2.5 times that of $Q_{0}$. Then ozone production decreases with decreasing $\mathrm{NO}$ emission. Figure 6 gives the relation be5 tween $\mathrm{O}_{3}$ and $\mathrm{NO}_{x}$ against different $\mathrm{NO}$ emission source strengths. Comparing with the PLUME case, the results indicate that at high $\mathrm{NO}_{\mathrm{x}}$ concentration, the production of $\mathrm{O}_{3}$ decreases with further $\mathrm{NO}_{x}$ emissions. This is expected when considering the contributions to the $\mathrm{NO}_{x} / \mathrm{VOC}$ chemistry through emissions and initial concentrations for both the PLUME and the URBAN cases. The two cases have different emission 10 strengths and initial concentrations of NO and VOCs, but both are very sensitive to these factors.

The URBAN/BIO case is intended to model the impact of an urban plume when passing a source of biogenic hydrocarbons. The first $60 \mathrm{~h}$ of URBAN/BIO is identical to the URBAN case, and the NO emission strength is $2.5^{\star} Q_{0}$. Then the anthropogenic 15 VOC emissions are switched off and the biogenic emission (of isoprene) is switched on. Calculations continue untill $t=120 \mathrm{~h}$. This simulation shows that the air parcels pick up anthropogenic emissions when passing an industrialized area and then transport them into a rural environment with biogenic emission. The production of $\mathrm{O}_{3}$ slows after the anthropogenic $\mathrm{VOC}$ emissions end, and $\mathrm{NO}_{\mathrm{x}}$ mixing ratio reduces rapidly afterwards 20 (see Fig. 7).

\section{Accuracy/Efficiency analysis}

This section addresses trade-offs between the efficiency and accuracy of CHEMEQ2. The comparison focuses on numerical efficiency and accuracy with one chemical mechanism, RACM, eliminating differences due to the chemistry modules. For a com25 parison of the mechanisms RACM and ReLACS, the reader may refer to Gross et al. (2003) and Geiger et al. (2002).

Numerical integration of troposphere photochemistry mechanism

F. Liu et al.

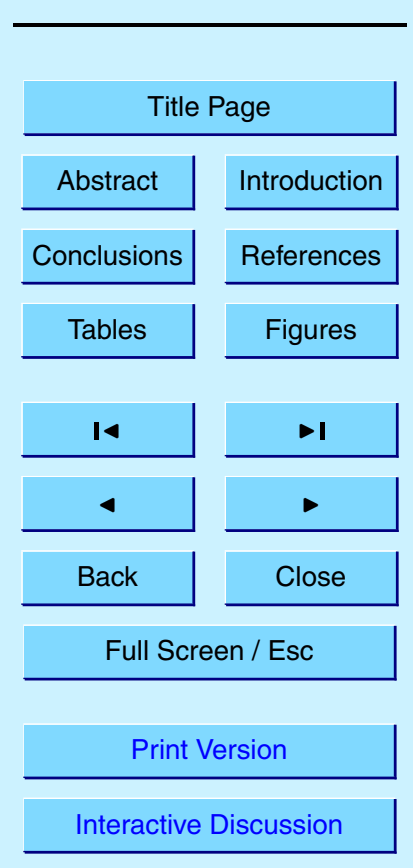


The relative difference between the simulations $n_{i}$ by CHEMEQ2 and the 'exact' solutions $n_{s i}$ by VODE are calculated for each global time step for eight chosen species $\mathrm{O}_{3}, \mathrm{NO}, \mathrm{NO}_{2}, \mathrm{HONO}, \mathrm{OH}, \mathrm{HCHO}, \mathrm{ALD}$, and PAN with the PLUME case. The relative 5 difference with respect to VODE integration is defined as

$R E R R_{i}=\frac{n_{s i}-n_{i}}{n_{s i}}$

In order to quantitatively identify the source of errors caused by internal parameter settings of the solver, a fixed global time step $\Delta t_{g}$ of $30 \mathrm{~min}$ is used. The influence of $\Delta t_{g}$ on accuracy and efficiency is discussed at the end of this section. Another way 10 to assess the accuracy of solver is to compare the difference between the simulations and 'exact' solutions for all apecies at the endpoint, i.e. after the integration time of $132 \mathrm{~h}$. As a global measure of this error, we calculate the "root mean square" (r.m.s) values by,

$e_{r . m . s}=\sqrt{\frac{\sum_{i=1}^{m} R E R R_{i}^{2}}{m}}$

15 where $m=77$ is the number of species in RACM. Figure 8 shows the $R E R R$ for 77 species at the end point of integration. Even though the accuracy parameter $\varepsilon=0.1$ and $\mathrm{Nc}=1$, the simulation of $\mathrm{O}_{3}$ is accurate enough and $R E R R_{\mathrm{O}_{3}}$ is $7.793 \%$. However the relative difference for $\mathrm{HNO}_{3}, \mathrm{HONO}, \mathrm{H}_{2} \mathrm{O}_{5}, \mathrm{NO}, \mathrm{NO}_{2}$ and $\mathrm{NO}_{3}$ exceed $50 \%$, and the accuracy of $\mathrm{HONO}$ and $\mathrm{N}_{2} \mathrm{O}_{5}$ are worst among all the species. $R E R R_{\mathrm{HONO}}$ and 20 $R E R R_{\mathrm{N} 2 \mathrm{O} 5}$ are $79.67 \%$ and $135 \%$, respectively. When $\varepsilon=0.01$ and $N c$ remains 1 , accuracy for all species is much improved. $R E R R_{\mathrm{O} 3}, R E R R_{\mathrm{HONO}}$ and $R E R R_{\mathrm{N} 2 \mathrm{O} 5}$ are $0.57 \%, 12.92 \%$ and $15.98 \%$, respectively. If $\varepsilon=0.005$ and $N c=5$ accuracy is further improved for all species but $\mathrm{O}_{3} . R E R R_{\mathrm{O} 3}$ is $0.59 \%$. The maximum relative difference
5, 6215-6262, 2005

Numerical integration of troposphere photochemistry mechanism

F. Liu et al.

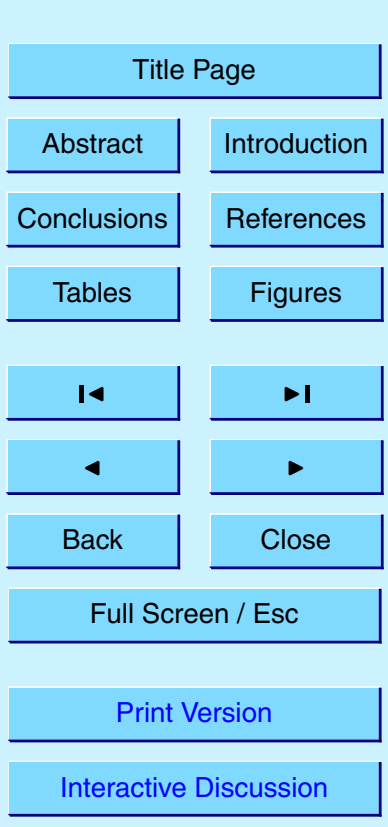

EGU 
is $7.40 \%$ corresponding to $R E R R_{\mathrm{XYL}} \cdot R E R R_{\mathrm{HONO}}$ and $R E R R_{\mathrm{N} 2 \mathrm{O} 5}$ are $0.95 \%$ and $1.92 \%$, respectively.

In order to look into detailed variations of relative difference we present the variations ACPD of $R E R R$ as a function of time for 8 species in Fig. 9. The analysis is carried out with 5 four accuracy levels. The relative difference of $\mathrm{O}_{3}$ is less than $10 \%$ even if $\varepsilon$ is 0.1 . But the RERRs for other species such as $\mathrm{NO}_{\mathrm{x}}, \mathrm{HONO}$, PAN, reach up to $60 \%, 90 \%$ and $30 \%$, respectively. This can be expected, since the RACM is designed to model tropospheric chemistry with $\mathrm{O}_{3}$ being the most important species. This also implies that it is not reasonable to evaluate a solver only with $\mathrm{O}_{3}$ concentration. Figure 10 10 shows that the accuracy for all species is greatly improved as $\varepsilon$ is decreased. When $\varepsilon$ is reduced to 0.01 the relative difference of $\mathrm{O}_{3}$ is less than $1 \%$ compared with the reference solutions. The RERRs for all species are decreased considerably. The RERRs for $\mathrm{NO}, \mathrm{NO}_{2}$ and $\mathrm{HONO}$ are less than $10 \%$, and for $\mathrm{HO}, \mathrm{HCHO}, \mathrm{ALD}$ and PAN less than $5 \%$. If a very accurate result is required and the added computational cost can be tolerated, in addition to lowering $\varepsilon$ increasing $N c$ is dramatically effective. The case with $\varepsilon=0.005$ and $N c=5$ gives more accurate simulations. However, further attempt to improve accuracy by decreasing $\varepsilon$ or increasing $N c$ does not produce any significant change in the results because CHEMEQ2 was designed to provide moderately accurate solutions at low computation costs. In addition lowering $\varepsilon$ is more efficient than increasing iterations $N c$ in improving accuracy if the CPU time is considered.

\subsection{Trade offs between efficiency and accuracy analysis}

The variation of root mean square $e_{\text {r.m.s }}$ and $\varepsilon$ against CPU time are shown in Fig. 10. The smaller the $e_{r . m . s}$ the more expensive of computation is. The $e_{r . m . s}$ decreases, for example, from $24.61 \%$ to $2.33 \%$ as the CPU time increases from $0.47 \mathrm{~s}$ to $3.03 \mathrm{~s}$. It can 25 be seen in Fig. 11 that CHEMEQ2 is more efficient than VODE by at least a factor of 10 and is much faster especially at low level of accuracy. CHEMEQ2 is more expensive as the level of accuracy increases. The current tests suggest that VODE works better than CHEMEQ2 for $\varepsilon<1 \%$.

Numerical integration of troposphere photochemistry mechanism

F. Liu et al.

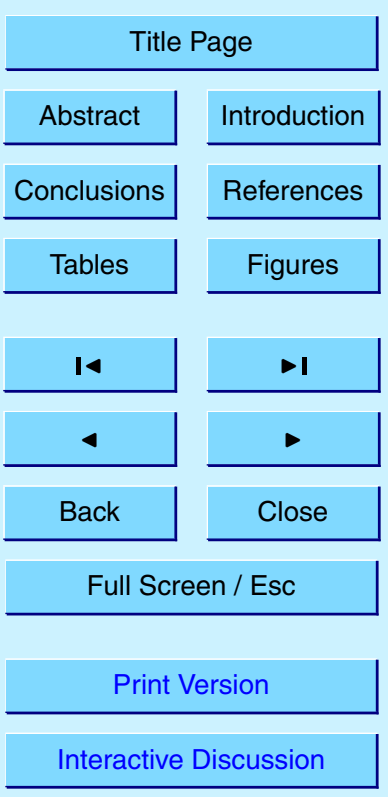

EGU 
Both the accuracy and the efficiency are affected not only by internal parameters like $\varepsilon$ and $N c$ but also by the global time step $\Delta t_{g}$. This is expected from the $\alpha$-QSS method and the stiffness definition. The stiffness, as the characteristic of the system and not a specific problem, is highly influenced the time scales of the system. The time 5 scale that ultimately governs the evolution of the solution must be compared to the time scale that limits the timestep of the numerical method. The box model is run as if it was used in each grid point in an operator splitting environment. At every new start for the integration of the solver, a global time step $\Delta t_{g}$ is equal to the transport time step in a multiple processes reactive flow. The end integration for each $\Delta t_{g}$ serves as the initial 10 concentrations for the next restart, so the chemistry integrator gets a new initial-value problem at each global time step in each computational cell. Since the global time step is usually shorter than the time required for the slowest mode to become exhausted, the work required of the integration is largely independent of exactly how slow these modes are. A more accurate measure of how expensive the integration is will come 15

from a comparison between the timestep required of the integrator and the global time step, not the ratio of the longest and shortest chemical time scales. One could increase the global time step as much as possible to improve the efficiency, particularly of multi-step integration schemes. There is, however, a loss of accuracy when the ratio $\Delta t / \Delta t_{g}$ is large, regardless of the choice of solver, because the physical conditions 20 effect the reaction rates are not well resc timestep to improve the accuracy, but the integration becomes more expensive. The trade-offs between accuracy and efficiency corresponding to the change of global time step is shown in Fig. 12. For three dimensional modeling the global time step must be generally fixed according to the time scale of the problem of interest. Therefore, the measures to improve accuracy by decreasing $\Delta t_{g}$ as used in box model are not available in CTM, which is solved numerically according to a specific temporal and spatial resolution regarding to certain scales of interest.

The relative difference for most species except $\mathrm{O}_{3}$ is influenced by $\Delta t_{g}$ significantly in the box model. The major species like $\mathrm{NO}, \mathrm{NO}_{2}, \mathrm{HONO}, \mathrm{PAN}$ and $\mathrm{N}_{2} \mathrm{O}_{5}$ simulations
ACPD

$5,6215-6262,2005$

Numerical integration of troposphere photochemistry mechanism

F. Liu et al.

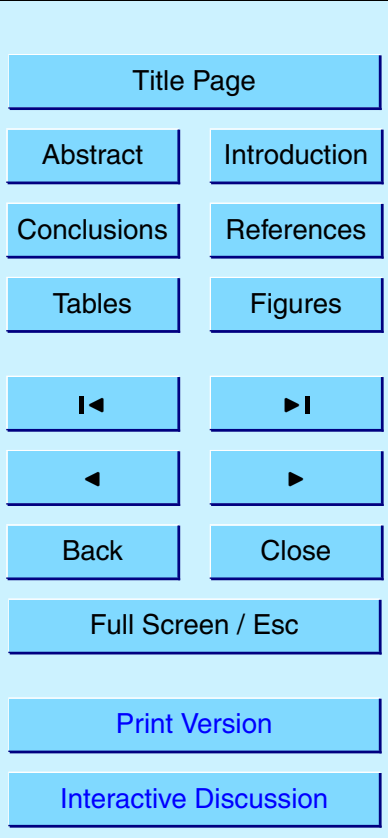


converge gradually to the reference results as decreasing of $\Delta t_{g}$ from $3 \mathrm{~h}$ to $5 \mathrm{~min}$. Obviously, when a too big global time step e.g. $\Delta t_{g}=3 \mathrm{~h}$, the simulations obtained by CHEMEQ2 will be too worse to be valid. In fact the largest global time step should not be bigger than $1 \mathrm{~h}$, a typical time resolution of $3 \mathrm{D}$ global model.

5 In addition comparison of the two mechanisms RACM and ReLACS shows that the efficiency will be improved greatly if RACM is replaced by ReLACS. Taking the PLUME scenario as an example, the RACM consumes $0.3505 \mathrm{~s}(\varepsilon=5 \%)$ and $1.6423 \mathrm{~s}(\varepsilon=1 \%)$, respectively, while the ReLACS only takes $0.1802 \mathrm{~s}(\varepsilon=5 \%)$ and $0.6710 \mathrm{~s}(\varepsilon=1 \%)$, respectively, which gives a $50 \%$ CPU time saving.

\section{Conclusions}

A box model is developed and tested as a first application of the integration scheme CHEMEQ2, which has been developed based on the $\alpha$-QSS algorithm, to the numerical integration of kinetic equations in tropospheric chemistry. Simulations are performed with the RACM and ReLACS gas-phase chemistry mechanisms under various 15 atmospheric conditions and then compared with simulations using the VODE scheme. Both schemes are designed for process-split reacting-flow simulation.

The results demonstrate that the $\alpha$-QSS scheme is efficient and relatively accurate in the solution of ODEs describing tropospheric chemistry. In the cases presented, when setting the relative error tolerance for CHEMEQ2 in the range from $5 \%$ to $1 \%$, 20 CHEMEQ2 agrees very well with VODE with a $r . m . s .<5 \%$ for all species in RACM as well as in ReLACS. CHEMEQ2 is at least 10-times faster than VODE when using the same global time step. CHEMEQ2, therefore, gives a comparable level of accuracy with a lower computational cost than VODE at moderate accuracy. VODE outperforms CHEMEQ2 when the higher level of accuracy $(\varepsilon<1 \%)$ is required. Since hydrodynamic

better candidate for integrating chemical ODEs coupled with expensive CTMs. The accuracy constraint in CHEMEQ2 does not measure the error directly but measures the
ACPD

$5,6215-6262,2005$

Numerical integration of troposphere photochemistry mechanism

F. Liu et al.

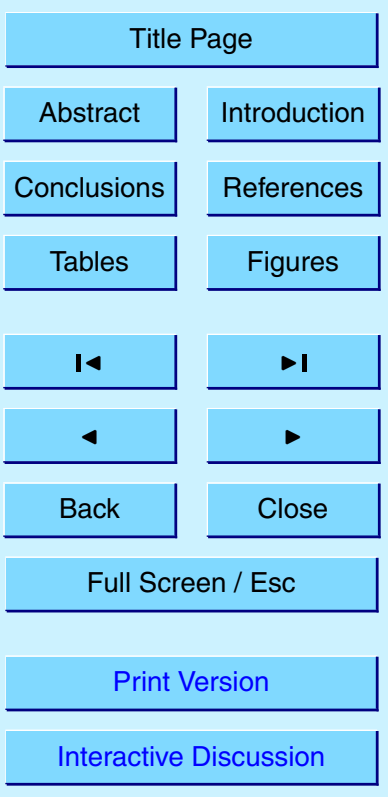

EGU 
correction to the predicted values provided by the corrector step. Therefore, experience with a particular mechanism is necessary to know how to set the optional parameters in CHEMEQ2 in order to produce a given level of accuracy in the solution. Future work will determine if these parameters are consistent between the box model and full 5 three-dimensional simulations and whether CHEMEQ2 outperforms other solvers for 3-D CTM.

The ReLACS will save at least 50\% CPU time compared against the RACM under the same conditions when the chemistry integration stands alone. The study also shows that the trade offs between accuracy and efficiency is influenced by the global time step 10 because it is related to the choice of the chemical time step for the integration.

Choosing a smaller global time step leads to a more accurate but more expensive integration. Conversely, this suggests that one should increase the global time step as much as possible to improve the efficiency. In practice, the global time step is chosen to accurately couple the various processes present in the simulation. Therefore, although the chemistry integration would be less expensive using a larger global time step, this time step is often set by other requirements in a reacting flow simulation. The solution approach must employ the most efficient chemistry integrator that meets the accuracy requirements of the application, subject to this time step constraint.

For the modeling study of ozone trends over the regions of interest the efficiency 20 of CTM is very important due to limited computational power but moderate accuracy is sufficient given the accuracy of other components in the model and the uncertainty in available experimental data. The solver CHEMEQ2 and the chemistry mechanism ReLACS will be the basic components for developing our next generation CTM for simulating long term change of ozone over the regions of interest.
ACPD

$5,6215-6262,2005$

Numerical integration of troposphere photochemistry mechanism

F. Liu et al.

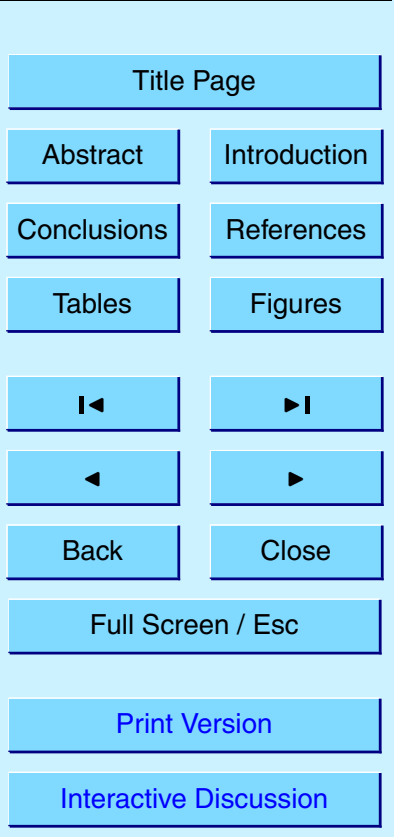




\begin{tabular}{|c|c|c|c|c|}
\hline \multicolumn{5}{|c|}{ RACM and ReLACS species list } \\
\hline & Oxidants & & & Stable Inorganic Compounds \\
\hline 1 & $\mathrm{O}_{3}$ & 1 & $\mathrm{O}_{3}$ & Ozone \\
\hline 2 & $\mathrm{H}_{2} \mathrm{O}_{2}$ & 2 & $\mathrm{H}_{2} \mathrm{O}_{2}$ & Hydrogen peroxide \\
\hline & Nitrogenous compou & & & \\
\hline 3 & NO & 3 & NO & nitric oxide \\
\hline 4 & $\mathrm{NO}_{2}$ & 4 & $\mathrm{NO}_{2}$ & Nitrogen dioxide \\
\hline 5 & $\mathrm{NO}_{3}$ & 5 & $\mathrm{NO}_{3}$ & Nitrogen trioxide \\
\hline 6 & $\mathrm{~N}_{2} \mathrm{O}_{5}$ & 6 & $\mathrm{~N}_{2} \mathrm{O}_{5}$ & Dinitrogen pentoxide \\
\hline 7 & HONO & 7 & HONO & nitrous acid \\
\hline 8 & $\mathrm{HNO}_{3}$ & 8 & $\mathrm{HNO}_{3}$ & Nitric acid \\
\hline 9 & $\mathrm{HNO}_{4}$ & 9 & $\mathrm{HNO}_{4}$ & pernitric acid \\
\hline & Sulfur compounds & & & \\
\hline 10 & $\mathrm{SO}_{2}$ & 10 & $\mathrm{SO}_{2}$ & sulphur dioxide \\
\hline 11 & SULF & & & sulphuric acid \\
\hline & Carbon oxides & & & \\
\hline 12 & $\mathrm{CO}$ & 11 & $\mathrm{CO}$ & carbon monoxide \\
\hline 13 & $\mathrm{CO}_{2}$ & & & carbon dioxide \\
\hline & & & & Abundant Stable Species \\
\hline 14 & $\mathrm{~N}_{2}$ & & & Nitrogen \\
\hline 15 & $\mathrm{O}_{2}$ & & & Oxygen \\
\hline 16 & $\mathrm{H}_{2} \mathrm{O}$ & & & Water \\
\hline 17 & $\mathrm{H}_{2}$ & & & Hydrogen \\
\hline & & & & Inorganic Short-Lived Intermediates \\
\hline 18 & $\mathrm{O}^{3} \mathrm{P}$ & & & ground state atom \\
\hline 19 & $\mathrm{O}^{1} \mathrm{D}$ & & & excited state oxygen atom \\
\hline & Odd hydrogen & & & \\
\hline 20 & $\mathrm{HO}$ & & & hydroxyl radical \\
\hline 21 & $\begin{array}{c}\mathrm{HO}_{2} \\
\text { Alkanes }\end{array}$ & 12 & $\mathrm{HO}_{2}$ & hydroperoxy radical \\
\hline 22 & $\mathrm{CH} 4$ & 13 & $\mathrm{CH} 4$ & Methane \\
\hline 23 & ETH & 14 & ETH & Ethane \\
\hline 24 & $\mathrm{HC} 3$ & 15 & ALKA & alkanes, alcohols, esters, and alkynes ${ }^{1}$ \\
\hline 25 & HC5 & & & alkanes, alcohols, esters, and alkynes ${ }^{2}$ \\
\hline 26 & $\begin{array}{c}\text { HC8 } \\
\text { Alkenes }\end{array}$ & & & alkanes, alcohols, esters, and alkynes ${ }^{3}$ \\
\hline 27 & ETE & 16 & ETE & Ethane \\
\hline 28 & OLT & & & Terminal alkenes \\
\hline 29 & OLI & & & Internal alkenes \\
\hline 30 & DIEN & & & Butadiene and other anthropogenic dienes \\
\hline
\end{tabular}

5, 6215-6262, 2005

Numerical integration of troposphere photochemistry mechanism

F. Liu et al.

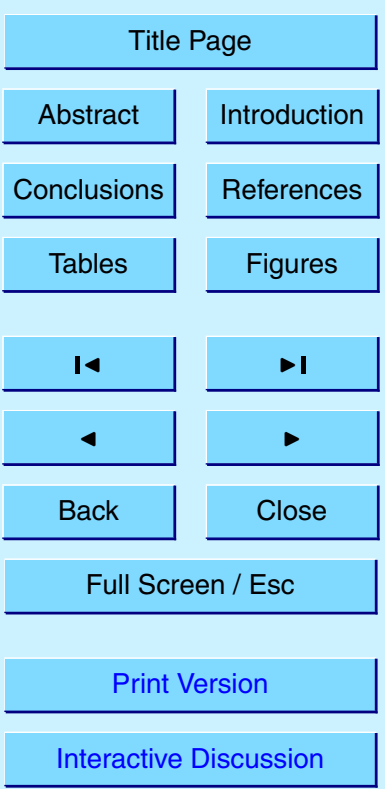




\begin{tabular}{|c|c|c|c|c|}
\hline No & RACM & No & $\begin{array}{l}\text { CM and } R \epsilon \\
\text { ReLACS }\end{array}$ & ACS species list \\
\hline \multicolumn{5}{|c|}{ Stable biogenic alkenes } \\
\hline 31 & ISO & 17 & $\mathrm{BIO}$ & Isoprene \\
\hline 32 & $\mathrm{API}$ & & & $\alpha$-pinene and other cyclic terpenes with one double bond \\
\hline 33 & LIM & & & d-limoene and other cyclic diene-terpenes \\
\hline \multicolumn{5}{|c|}{ Aromatics } \\
\hline 34 & TOL & 18 & ARO & Toluene \\
\hline 35 & XYL & & & Xylene \\
\hline 36 & CSL & & & cresol and other aromatics \\
\hline \multicolumn{5}{|c|}{ Carbonyls } \\
\hline 37 & $\mathrm{HCHO}$ & 19 & $\mathrm{HCHO}$ & Formaldehyde \\
\hline 38 & ALD & 20 & ALD & acetaldehyde and higher aldehydes \\
\hline 39 & KET & 21 & KET & Ketones \\
\hline 40 & GLY & 22 & CARBO & Glyoxal \\
\hline 41 & MGLY & & & methyglyoxal and other $\alpha$-carbonyl aldehydes \\
\hline 42 & DCB & & & unsaturated dicarbonyls \\
\hline 43 & MACR & & & metacrolein and other unsaturated monoaldehydes \\
\hline 44 & UDD & & & unsaturated dihydroxy dicarbonyl \\
\hline 45 & HKET & & & hydroxyl ketone \\
\hline \multicolumn{5}{|c|}{ Organic nitrogen } \\
\hline 46 & ONIT & 23 & ONIT & organic nitrate \\
\hline 47 & PAN & 24 & PAN & peroxyacetyl nitrate and higher saturated PANs \\
\hline 48 & TPAN & & & unsaturated PANs \\
\hline \multicolumn{5}{|c|}{ Organic peroxides } \\
\hline 49 & OP1 & 25 & & methyl hydrogen peroxide \\
\hline 50 & OP2 & 26 & & higher organic peroxides \\
\hline 51 & PAA & & & peroxyacetic acid and higher analogs \\
\hline \multicolumn{5}{|c|}{ Organic acids } \\
\hline 52 & ORA1 & & & formaic acid \\
\hline \multirow{2}{*}{\multicolumn{5}{|c|}{$\begin{array}{l}\text { acetic and higher acids } \\
\text { Organic Short-Lived Intermediates }\end{array}$}} \\
\hline & & & & \\
\hline 54 & MO2 & 28 & MO2 & methyl peroxy radical \\
\hline 55 & ETHP & 29 & ALKAP & peroxy radicals formed from ALKA \\
\hline 56 & HC3P & & & peroxy radicals formed from $\mathrm{HC} 3$ \\
\hline 57 & HC5P & & & peroxy radicals formed from HC5 \\
\hline 58 & HC8P & & & peroxy radicals formed from $\mathrm{HC} 8$ \\
\hline \multicolumn{5}{|c|}{ Peroxy radicals from alkenes } \\
\hline 59 & ETEP & 30 & ALKEP & peroxy radicals formed from ALKE \\
\hline 60 & OLTP & & & peroxy radicals formed from OLT \\
\hline 61 & OLIP & & & peroxy radicals formed from OLI \\
\hline
\end{tabular}

ACPD

5, 6215-6262, 2005

Numerical integration

of troposphere

photochemistry

mechanism

F. Liu et al.

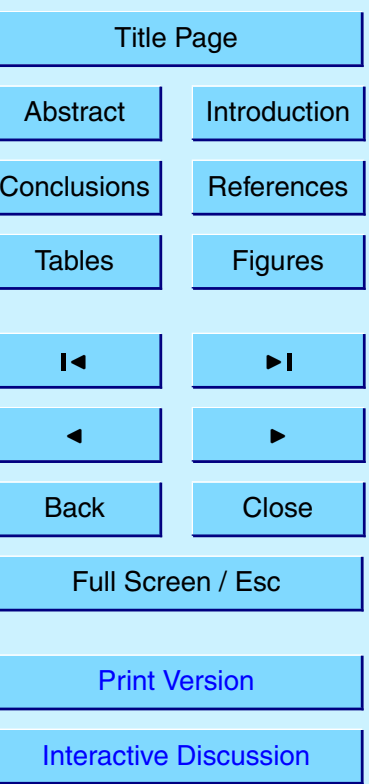




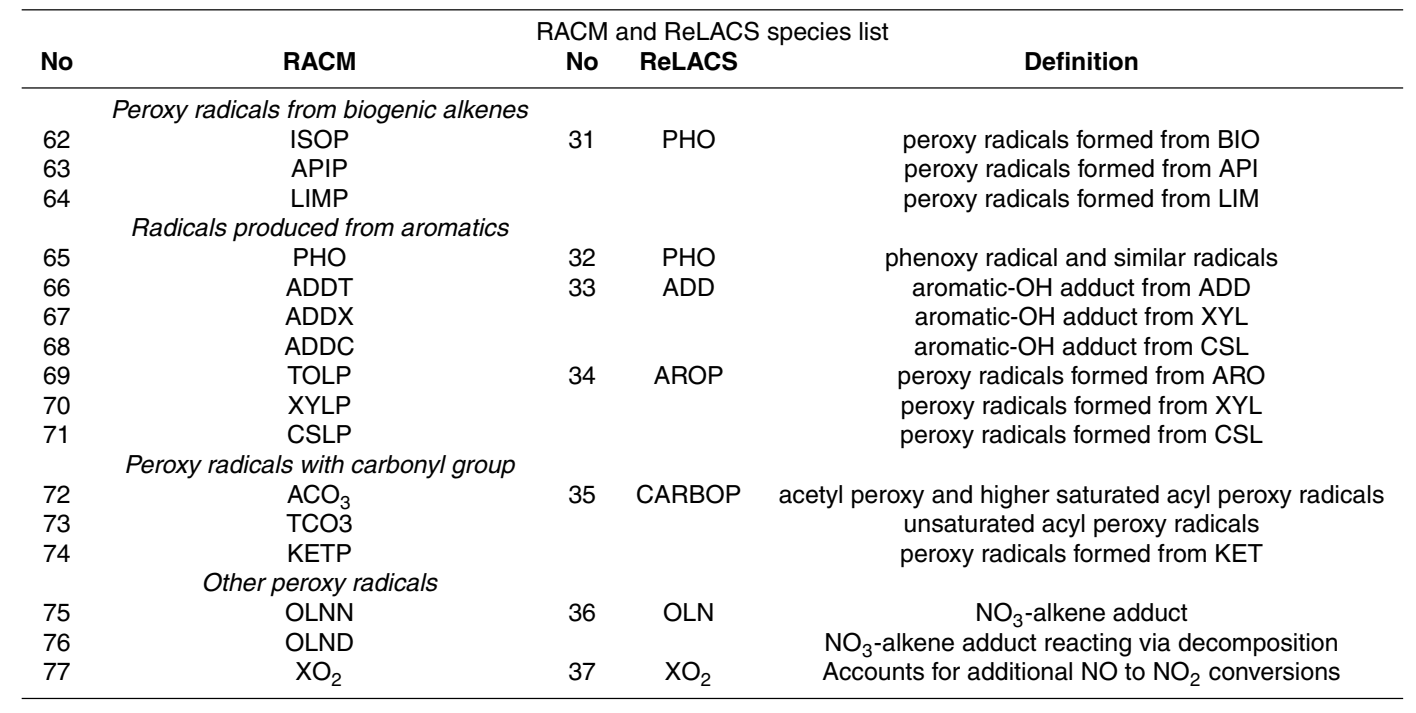

${ }^{1}$ with HO rate constant less than $3.4 \times 10^{-12} \mathrm{~cm}^{3} \mathrm{~s}^{-1}$

2 with $\mathrm{HO}$ rate constant between $3.4 \times 10^{-12}$ and $6.8 \times 10^{-12} \mathrm{~cm}^{3} \mathrm{~s}^{-1}$

${ }^{3}$ with $\mathrm{HO}$ rate constant greater than $6.8 \times 10^{-12} \mathrm{~cm}^{3} \mathrm{~s}^{-1}$

5 Acknowledgements. We thank W. Stockwell for providing RACM and access to his Sbox model. We also thank C. Mari for providing ReLACS and helpful discussion. We are grateful for the suggestion from D. Poppe and Y. Liu.

\section{References}

Avro, C. G.: A stiff ODE solver for the equations of chemical kinetics, Computer Physics Communications, 97, 304-314, 1996.

Brown, P. N., Byrne, G. D., and Hindmarsh, A. C.: VODE: A variable coefficient ODE Solver, SIAM J. Sci. Stat. Comput., 10, 1038-1051, 1989.

\section{ACPD}

$5,6215-6262,2005$

Numerical integration

of troposphere

photochemistry

mechanism

F. Liu et al.
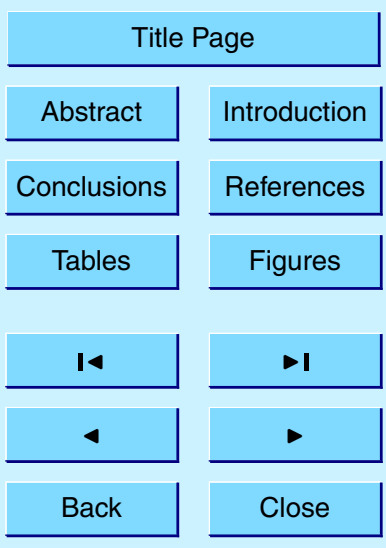

Full Screen / Esc

Print Version

Interactive Discussion 
Geiger, H., Barnes I., Becker, K. H., et al.: Chemical mechanism development: Laboratory studies and model application, J. Atmos. Chem., 42, 323-357, 2002.

Crassier, V., Suhre, K., Tulet, P., and Rosset, R.: Development of a reduced chemical scheme for use in mesoscale meteorological model, Atmos. Environ., 34, 2633-2644, 2000.

5 Derwent, R. G. and Jenkin, M. E.: Hydrocarbons and the long-range transport of ozone and PAN across Europe, Atmos. Environ., 25A(8), 1661-1678, 1991.

Derwent, R. G., Jenkin, M. E., Saunders, S. M., and Pilling, M. J.: Photochemical ozone creation potientials for organic compounds in northwest Europe calculated with a master chemical mechanism, Atmos. Environ., 32, 2429-2441, 1998.

10 Gear, C. W.: Numerical initial value problems in ordinary differential equations, Prentice-Hall, Englewood Cliffs, New Jersey, 1971.

Gery, M. W., Whitten, G. Z., Killus, J. P., and Dodge, M. C.: A photochemical kinetics mechanism for urban and regional scale computer modelling, J. Geophys. Res., 94, 12 925-12 956, 1989.

Gross, A. and Stockwell, W.: Comparison of EMEP, RADM2 and RACM Mechanisms, J. Atmos. Chem., 44, 151-170, 2003.

Hairer, E. and Wanner, G.: Solving ordinary differential equations II. Stiff and DifferentialAlgebraic Problems, Spring-Verlag, Berlin, 1991.

Hertel, O., Berkowicz, R., Christensen, J., and Hov, Ø.: Test of two chemical schemes for use in atmospheric transport chemistry models, Atmos. Environ., 27A, 2591-2611, 1993.

Hindmarsh, A. C.: ODEPACK, a systematic collection of ODE solvers, in: Numerical methods for scientific computation, edited by: Stepleman, R. S., North Holland, New York, 55-64, 1983.

Hindmarsh, A. C. and Norsett, S. P.: KRYSI, An ODE Solver Combining a Semi-Implicit Runge$25 \quad$ Kutta Method and a Preconditioned Krylov Method, LLNL report UCID-21422, 1988.

Jay, L. O., Sandu, A., Porta, F. A., and Carmichael, G. R.: Improved Quasi-Steady-StateApproximation methods for atmospheric chemistry integration, SIAM Journal of Scientific Computing, 18, 182-202, 1997.

Jenkin, M. E., Saunders, S. M., and Pilling, M. J.: The Tropospheric degradation of volatile organic compounds: A protocol for mechanism development, Atmos. Environ., 31, 81-104, 1997.

Jimenez, P., Baldasano, J. M., and Dabdub, D.: Comparison of photochemical mechanisms for air quality modelling, Atmos. Environ., 37, 4179-4194, 2003.

ACPD

5, 6215-6262, 2005

Numerical integration of troposphere photochemistry mechanism

F. Liu et al.

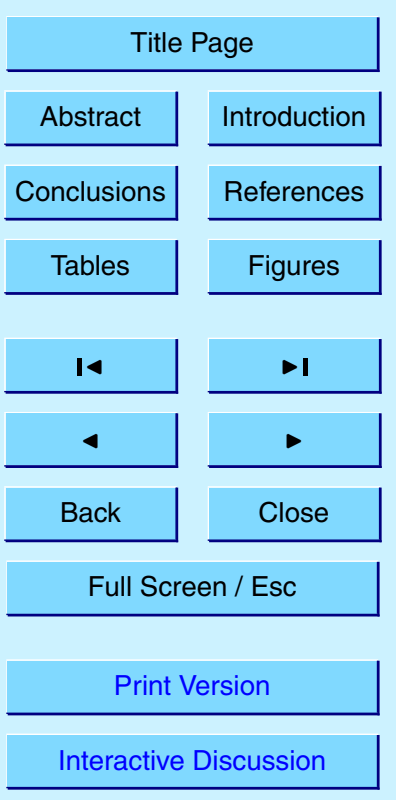

EGU 
Kohlmann, J. P. and Poppe, D.: The tropospheric gas-phase degradation of $\mathrm{NH}_{3}$ and its impact on the formation of $\mathrm{N}_{2} \mathrm{O}$ and $\mathrm{NO}_{x}$. J. Atmos. Chem., 32, 397-415, 2003.

Kuhn, M., Builtjes, P. J. H., Poppe, D., et al.: Intercomparison of the gas-phase chemistry in several chemistry and transport models, Atmos. Environ., 32(4), 693-709, 1998.

5 Lorenzini, R. and Passoni, L.: Test of numerical methods for the integration of kinetic equations in tropospheric chemistry, Computer Physics Communications, 117, 241-249, 1999.

Lurmann, F. W., Lloyd, A. C., and Atkinson, R.: A chemical mechanism for use in long-range transport/acid deposition computer modelling, J. Geophys. Res., 91, 10 905-10 936, 1986.

Mott, D. R., Oran, E. S., and van Leer, B.: A Quasi-Steady-State Solver for the Stiff Ordinary 10 Differential Equations of Reaction Kinetics, Journal of Computational Physics, 164, 407-428, 2000.

Mott, D. R. and Oran, E. S.: CHEMEQ2: A solver for the stiff ordinary differential equations of chemical kinetics, NRL Memorandum Report No. 6400-01-8553, 2001.

Oran, E. S. and Boris, J. P.: Numerical simulation of reactive flow, Elservier Science Publishing 15 Co., Inc., New York, 1987.

Oran, E. S. and Boris, J. P.: Numerical simulation of reactive flow, Elservier Science Publishing Co., Inc., New York, 2000.

Poppe, D., Andersson-Sköld, Y., Baart, A., Builtjes, P. J. H., et al.: Gas-phase reactions in atmospheric chemistry and transport models: a model intercomparison, EUROTRAC Report, 201996.

Poppe, D., Aumont, B., Ervens, B., et al.: Scenarios for modeling multiphase tropospherical chemistry, J. Atmos. Chem., 40, 77-86, 2001.

Radhakrishnan, K. and Pratt, D. T.: Fast algorithm for calculating chemical kinetics in turbulent reacting flow, Combustion Science and Technology, 58, 155-176, 1988.

Radhakrishnan, K. and Hindmarsh, A. C.: Description and Use of LSODE, the Livermore Solver for Ordinary Differential Equations, LLNL report UCRL-ID-113855, 1993.

Sandu, A., Potra, F. A., Damian, V., and Carmichael, G. R.: Efficient implementation of fully implicit methods for atmospheric chemistry kinetics. Reports on computational mathematics, No. 79/1995, The Uni. of lowa, 1995.

so Sandu, A., Verwer, J. G., van Loon, M., Carmichael, G. R., Potra, F. A., Dabdub, D., and Seinfeld, J. H.: Benchmarking stiff ODE solvers for atmospheric chemistry problems I: Implicit versus explicit, NM-R9614, 1996.

Saylor, R. D. and Ford, G. D.: On the comparison of numerical methods for the integration

ACPD

$5,6215-6262,2005$

Numerical integration of troposphere photochemistry mechanism

F. Liu et al.

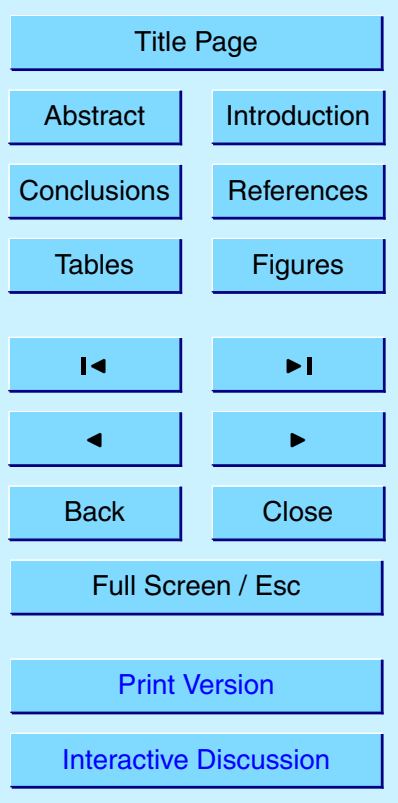

EGU 
of kinetic equations in atmospheric chemistry and transport models, Atmos. Environ., 29, 2585-2593, 1995.

Seefeld, S. and Stockwell, W.: First-order sensitivity analysis of models with time-dependent parameters: an application to PAN and ozone, Atmos. Environ., 33, 2941-2953, 1999.

5 Shyan-Shu Shield, D., Chang, Y., and Carmicael, G. R.: The evaluation of numerical techniques for solution of stiff ODE arising from chemical kinetic problems, Envir. Sof., 3, 28-38, 1988.

Simpson, D., Andersson-Sköld, Y., and Jenkin, M. E.: Updating the chemical scheme for the EMEP MSC-W oxidant model: current status, EMEP MSC-W Note 2/93, Norwegian Meteorological Institute, Oslo, Norway, 1993.

10 Stockwell, W. R., Middleton, P., Chang, J. S., and Tang, X.: The second generation regional acid deposition model chemical mechanism for regional air quality modelling, J. Geophys. Res., 95, 16343-16 367, 1990.

Stockwell, W. R. and Kley, D.: The Euro-RADM Mechanism: A gas-phase chemical mechanism for European air quality studies, Forschungzentrum Jülich GmbH (KFA), Jülich, Germany, 151994.

Stockwell, W. R., Krichner, F., Kuhn, M., and Seefeld, S.: A new mechanism for regional atmospheric chemistry modeling, J. Geophys. Res., 102(D22), 25 847-25 879, 1997.

Verwer, J. G. and van Loon, M.: An evaluation of explicit Psuedo-Steady-State Approximation Schemes for Stiff ODE Systems from Chemical Kinetics, Journal of Computational Physics, $20 \quad 113,347-352,1994$.

Verwer, J. G. and Simpson, D.: Explicit methods for stiff ODEs from atmospheric chemistry, Applied Numerical Mathematics, 18, 413-430, 1995.

Verwer, J. G., Blom, J. G., van Loon, M., and Spee, E. J.: A comparison of stiff ODE solvers for atmospheric chemistry problems, NM-R9505, 1995.

Young, T. R.: CHEMEQ - A subroutine for solving stiff ordinary differential equations, NRL Memorandum Report No. 4091, 1980.

Young, T. R. and Boris, J. P.: A numerical technique for solving stiff ordinary differential equations associated with the chemical kinetics of reactive-flow problems, J. Phys. Chem., 81, 2424-2427, 1977.

ACPD

$5,6215-6262,2005$

Numerical integration of troposphere photochemistry mechanism

F. Liu et al.

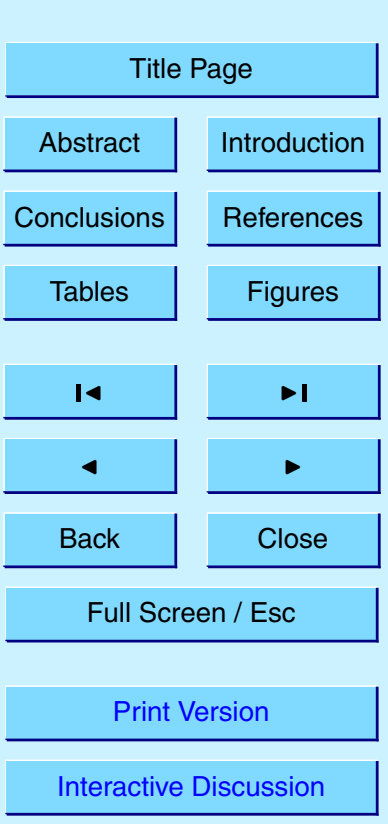




\section{ACPD}

5, 6215-6262, 2005

Numerical integration

of troposphere

photochemistry

mechanism

Table 1. Scenarios description.

F. Liu et al.

\begin{tabular}{clcc}
\hline Scenarios & Short description & Emissions & j-values \\
\hline LAND & continental planetary boundary layer with & no & Prescribed \\
& a low burden of pollutants & & \\
MARINE & marine boundary layer & no & Prescribed \\
FREE & middle troposphere & no & Prescribed \\
PLUME & moderately polluted PBL & yes & Prescribed \\
URBAN & polluted PBL & yes & Prescribed \\
URBAN/BIO & URBAN plume with biogenic impact & yes & Prescribed \\
\hline
\end{tabular}

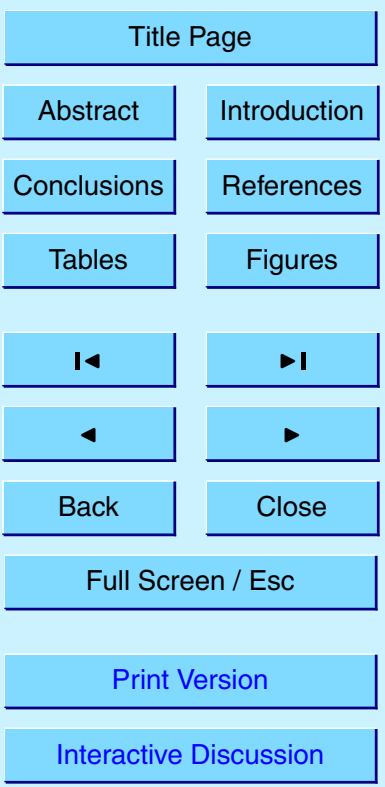




\section{ACPD}

5, 6215-6262, 2005

Numerical integration

of troposphere photochemistry mechanism

F. Liu et al.

Table 2. Modes for simulation.

\begin{tabular}{cccc}
\hline Mode & Mechanism & Solver & Note \\
\hline A & RACM & VODE & reference \\
B & RACM & CHEMEQ2 & Tests \\
C & ReLACS & CHEMEQ2 & Tests \\
\hline
\end{tabular}

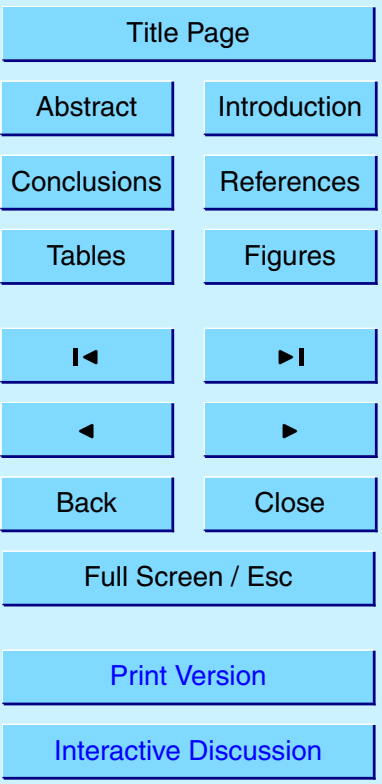




\section{ACPD}

Table 3. Emission data for cases PLUME, URBAN, and URBAN/BIO.

\begin{tabular}{cccc}
\hline Compounds & Emission strength $(\mathrm{ppb} / \mathrm{min})$ & Compounds & Emission strength $(\mathrm{ppb} / \mathrm{min})$ \\
\hline ALD & $0.36200 \mathrm{E}-04$ & KET & $0.31200 \mathrm{E}-03$ \\
CO & $0.56500 \mathrm{E}-02$ & NO & $0.25900 \mathrm{E}-02 \sim 0.012950^{\mathrm{a}}$ \\
TE & $0.45600 \mathrm{E}-03$ & OLI & $0.18800 \mathrm{E}-03$ \\
ETH & $0.24100 \mathrm{E}-03$ & OLT & $0.21900 \mathrm{E}-03$ \\
HC3 & $0.29100 \mathrm{E}-02$ & SO2 & $0.51800 \mathrm{E}-03$ \\
HC5 & $0.76900 \mathrm{E}-03$ & TOL & $0.57300 \mathrm{E}-03$ \\
HC8 & $0.45500 \mathrm{E}-03$ & XYL & $0.51900 \mathrm{E}-03$ \\
HCHO & $0.13900 \mathrm{E}-03$ & & \\
\hline
\end{tabular}

${ }^{a}$ For the PLUME case the NO emission strength, denote $Q_{0}$, is $0.25900 \mathrm{E}-02$ ( $\left.\mathrm{ppb} / \mathrm{min}\right)$. The strength is 5 times of $Q_{0}\left(Q=5 * Q_{0}=0.012950 \mathrm{ppb} / \mathrm{min}\right)$ for URBAN and URBAN/BIO cases.

$5,6215-6262,2005$

Numerical integration

of troposphere

photochemistry

mechanism

F. Liu et al.

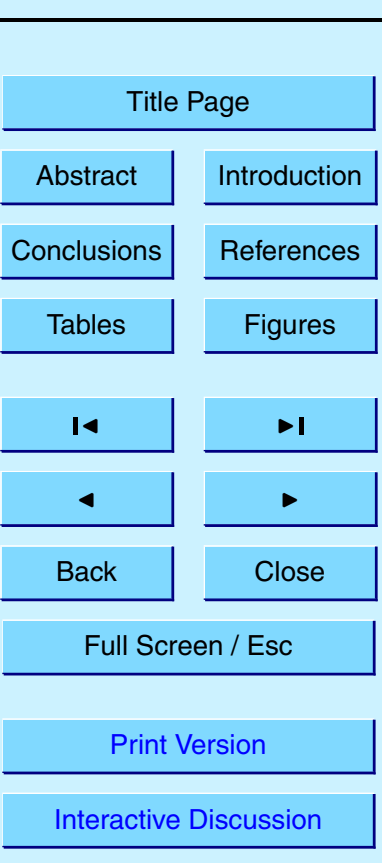

EGU 


\section{ACPD}

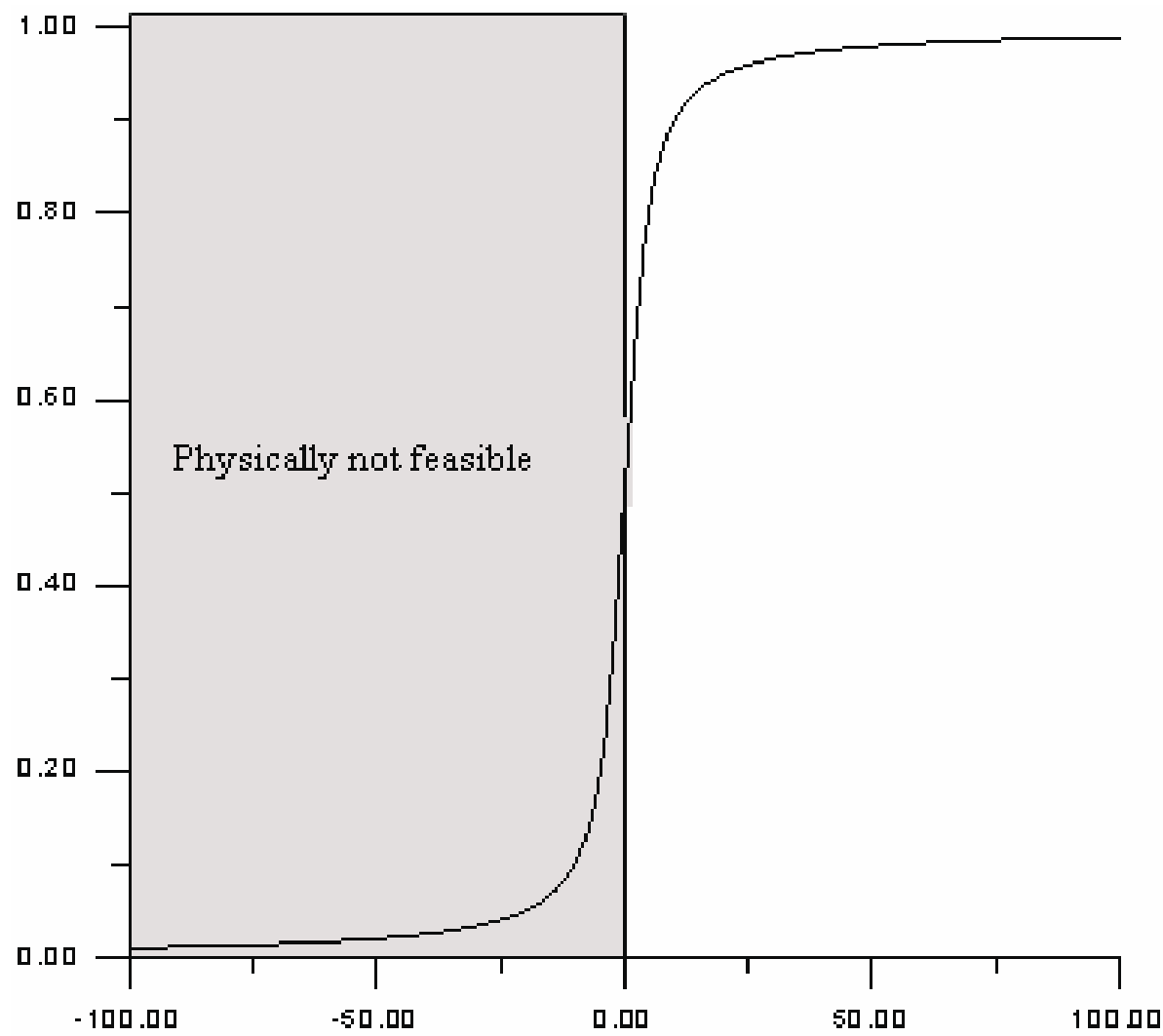

$5,6215-6262,2005$

Numerical integration

of troposphere photochemistry mechanism

F. Liu et al.

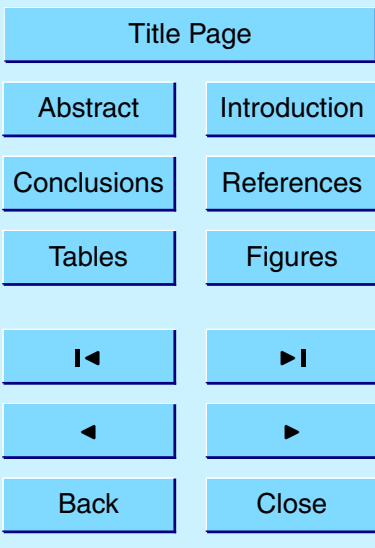

Full Screen / Esc

Print Version

Fig. 1. The parameter $\alpha$ (y-coordinator) as a function of $\Delta t / \tau$ (abscissa). 


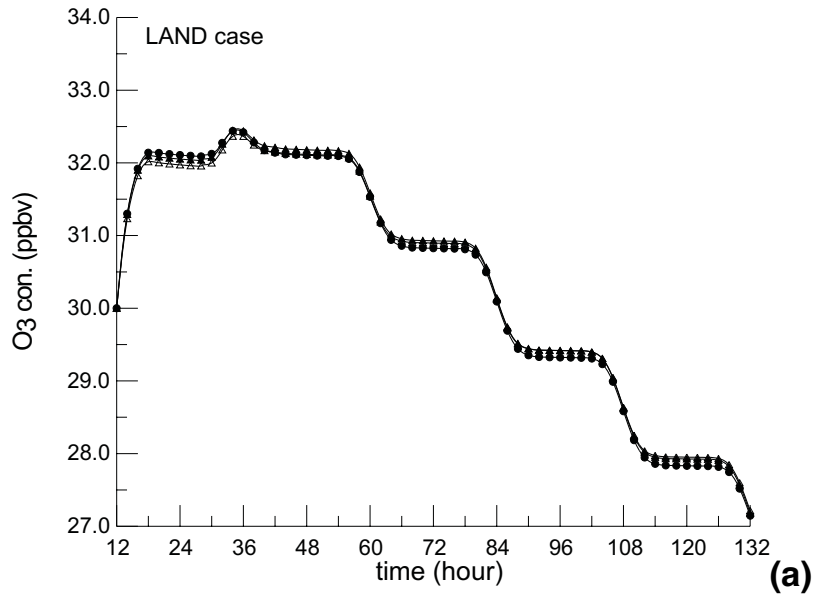

ACPD

5, 6215-6262, 2005

Numerical integration of troposphere photochemistry mechanism

F. Liu et al.
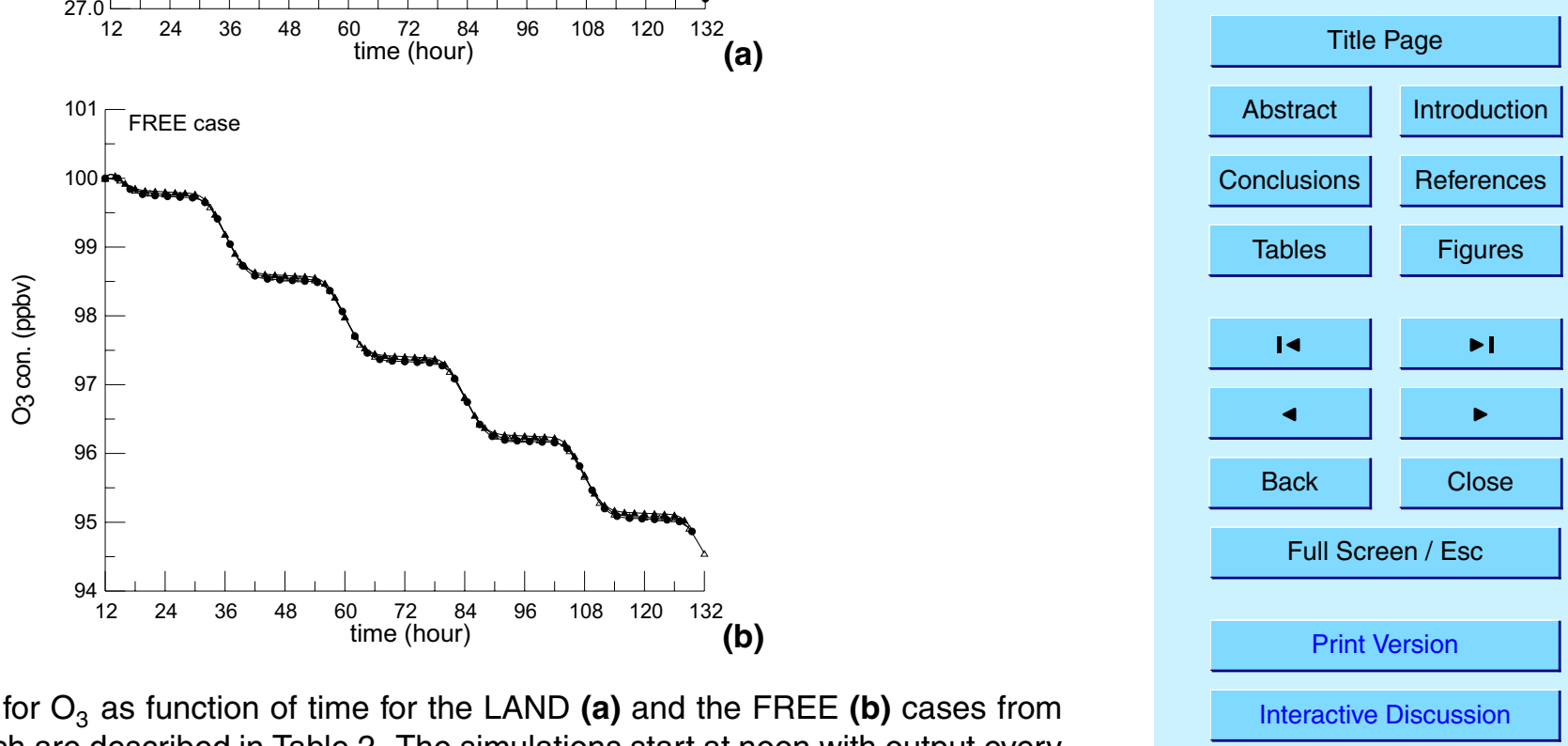

Fig. 2. Mixing ratio for $\mathrm{O}_{3}$ as function of time for the LAND (a) and the FREE (b) cases from different modes which are described in Table 2 . The simulations start at noon with output every

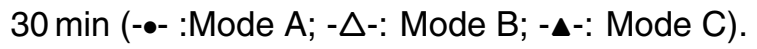




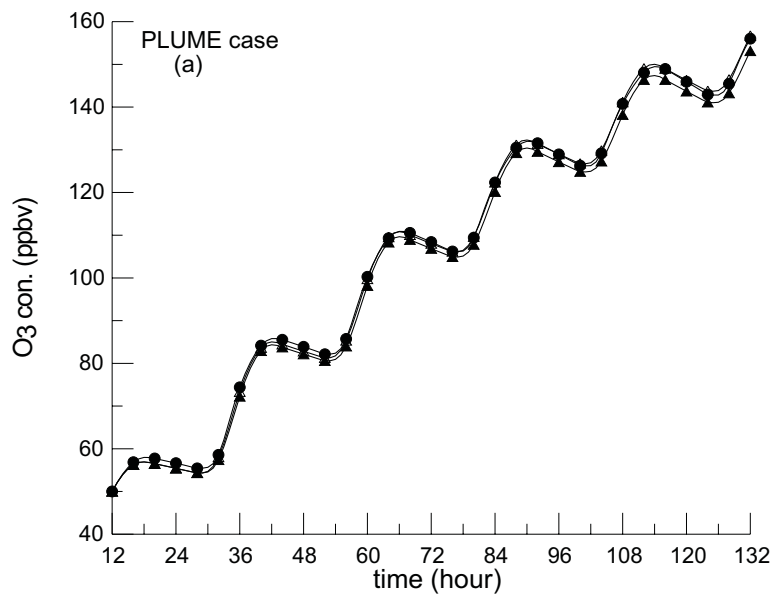

ACPD
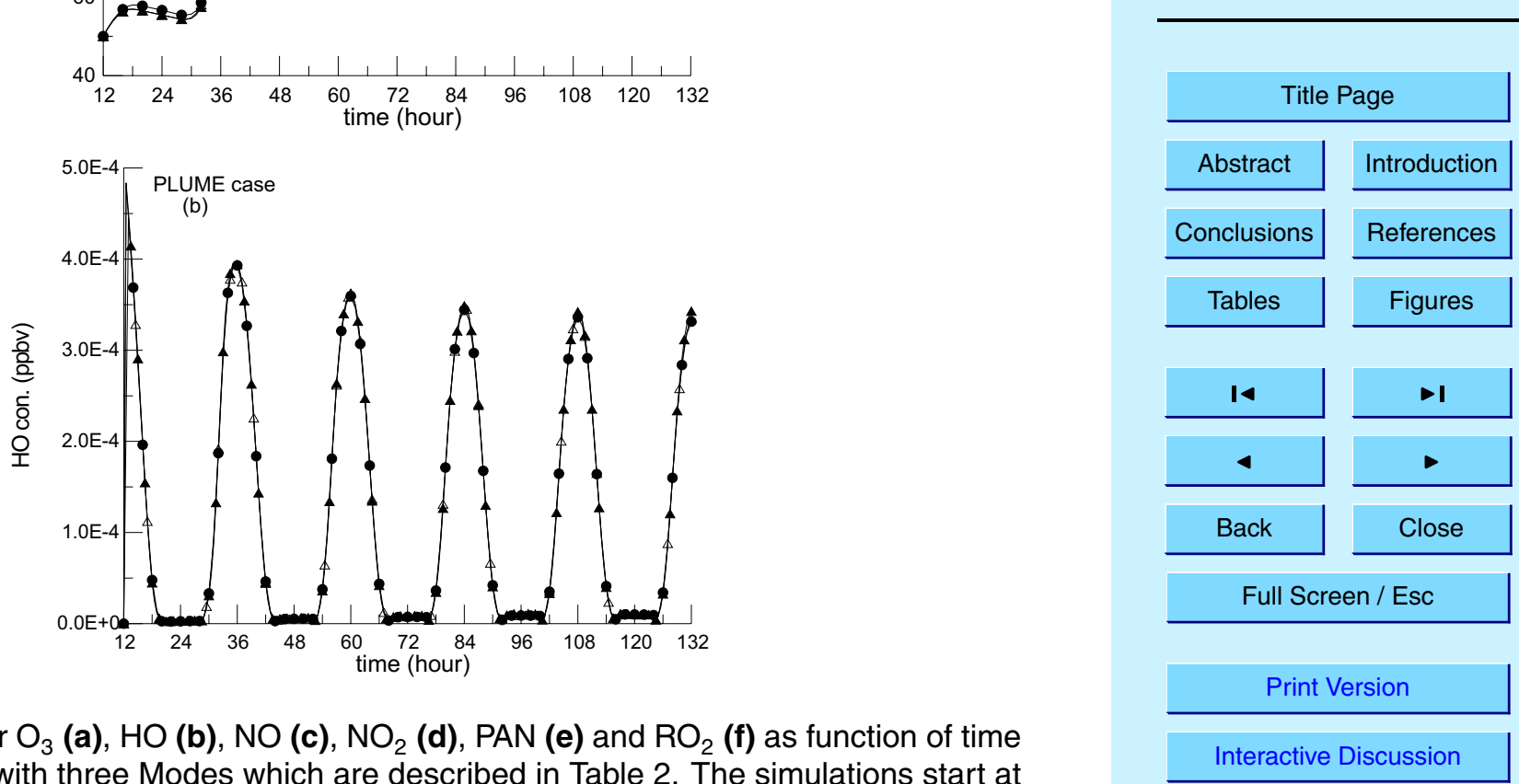

Fig. 3. Mixing ratio for $\mathrm{O}_{3}$ (a), $\mathrm{HO}(\mathbf{b}), \mathrm{NO}$ (c), $\mathrm{NO}_{2}$ (d), $\mathrm{PAN}(\mathbf{e})$ and $\mathrm{RO}_{2}$ (f) as function of time for the PLUME case with three Modes which are described in Table 2. The simulations start at

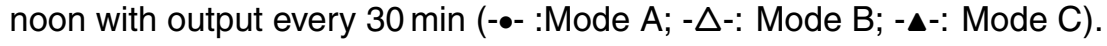

$5,6215-6262,2005$

Numerical integration of troposphere photochemistry mechanism

F. Liu et al. 


\section{ACPD}

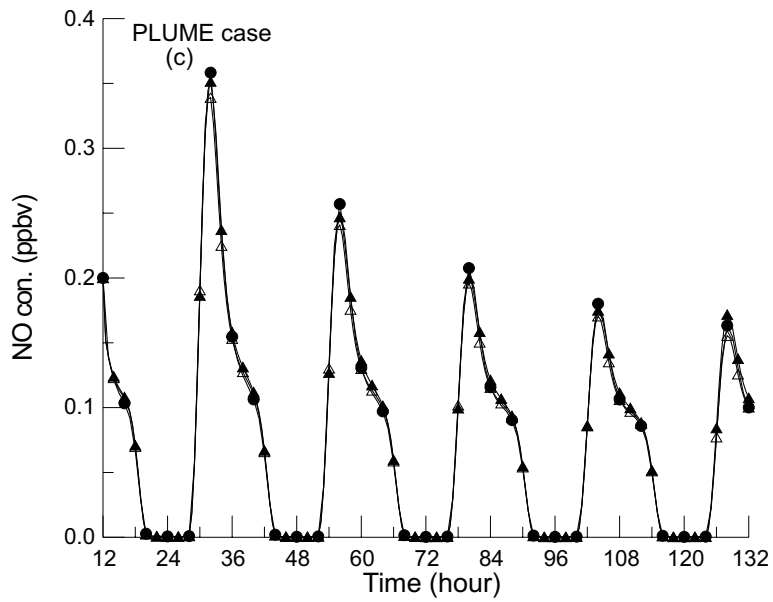

\section{5, 6215-6262, 2005}

\section{Numerical integration of troposphere photochemistry mechanism}

F. Liu et al.

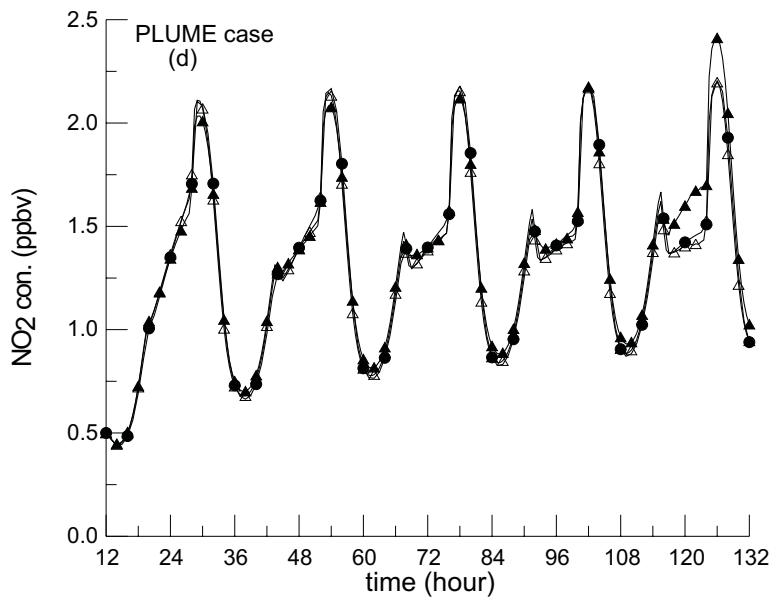

Title Page

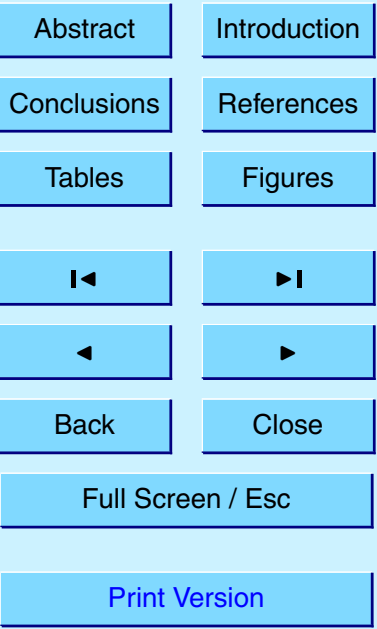

Interactive Discussion

Fig. 3. Continued. 


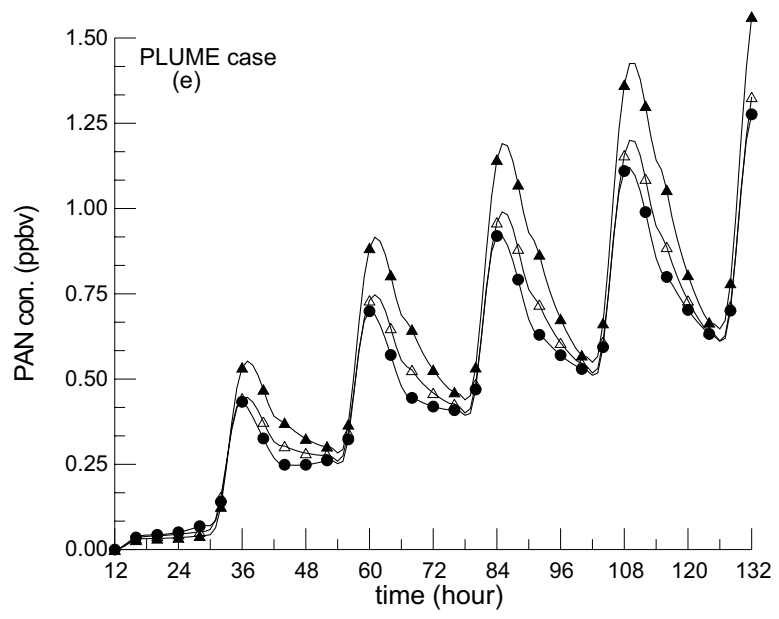

\section{ACPD}

5, 6215-6262, 2005

\section{Numerical integration of troposphere photochemistry mechanism}

F. Liu et al.

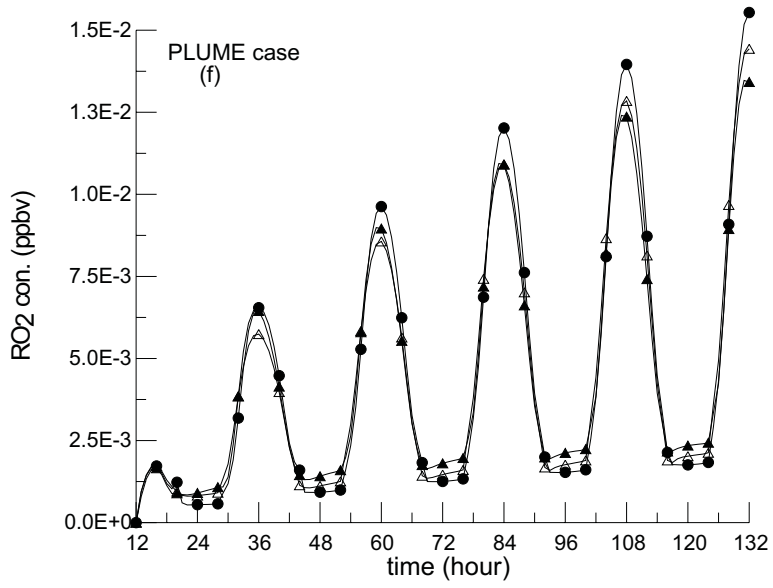

Title Page

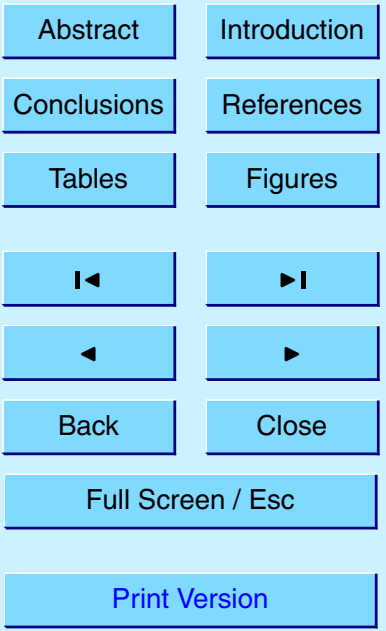

Interactive Discussion 


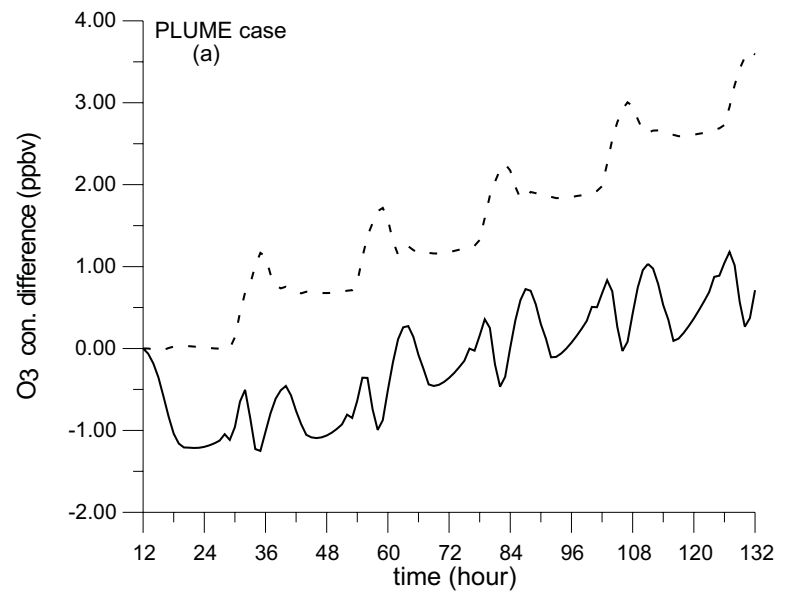

\section{ACPD}

$5,6215-6262,2005$

Numerical integration of troposphere photochemistry mechanism

F. Liu et al.
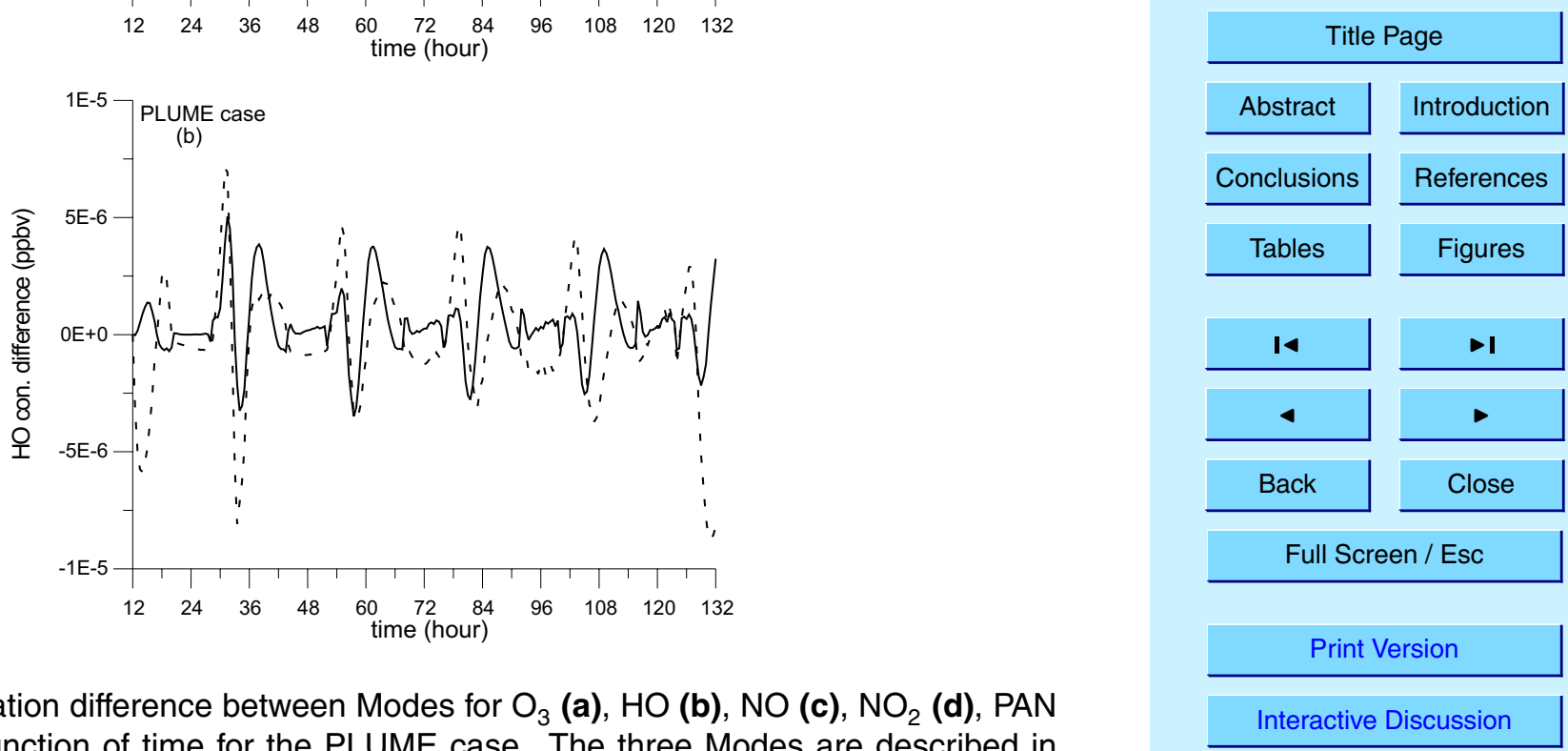

Fig. 4. The concentration difference between Modes for $\mathrm{O}_{3}$ (a), $\mathrm{HO}$ (b), $\mathrm{NO}$ (c), $\mathrm{NO}_{2}$ (d), PAN (e) and $\mathrm{RO}_{2}$ (f) as function of time for the PLUME case. The three Modes are described in Table 2. The simulations start at noon with output every 30 min (solid line: Mode B - Mode A; dashed line: Mode B - Mode C). 


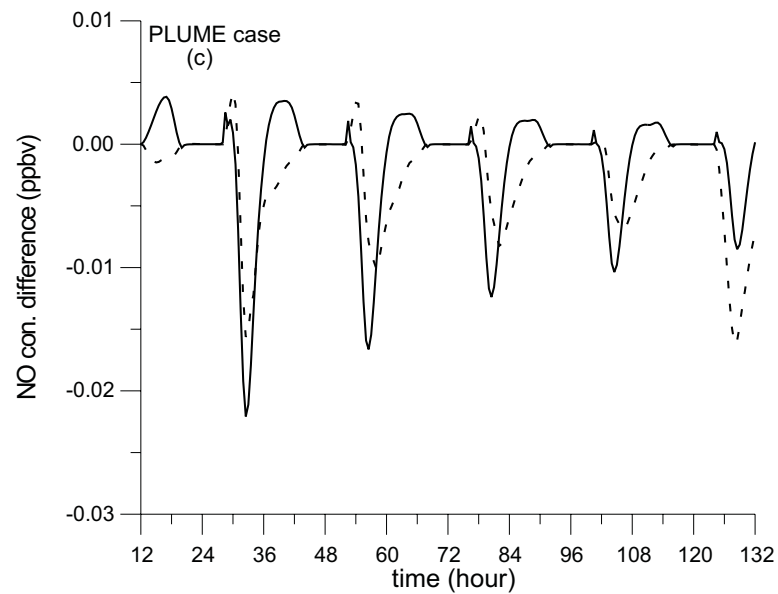

\section{ACPD}

5, 6215-6262, 2005

Numerical integration of troposphere photochemistry mechanism

\section{F. Liu et al.}

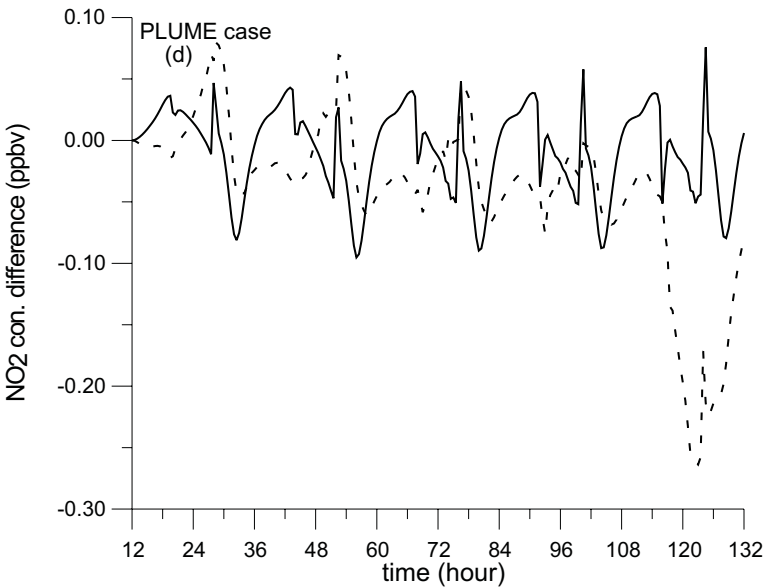

Title Page

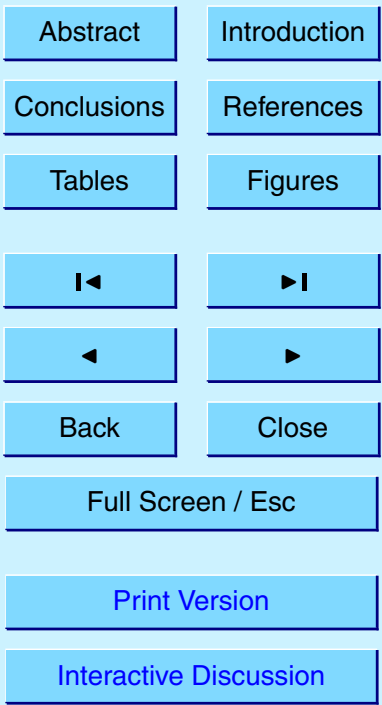

EGU 


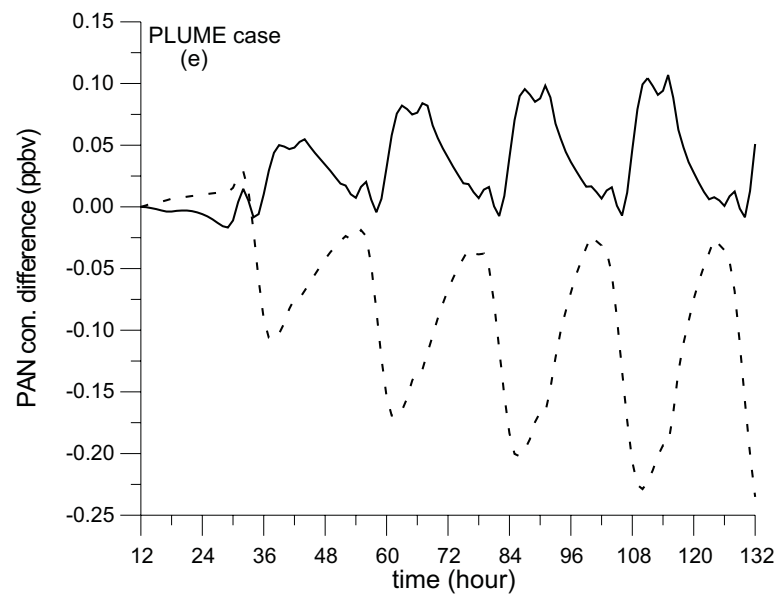

\section{ACPD}

5, 6215-6262, 2005

\section{Numerical integration of troposphere photochemistry mechanism}

F. Liu et al.

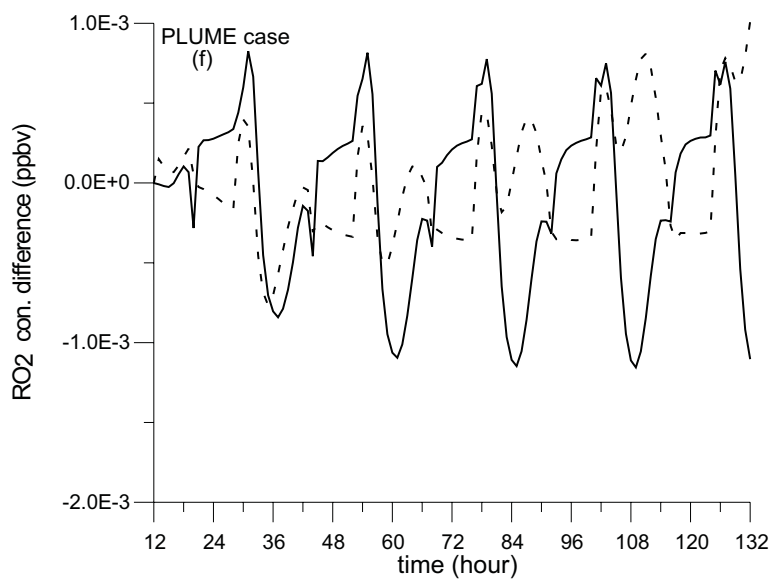

Title Page

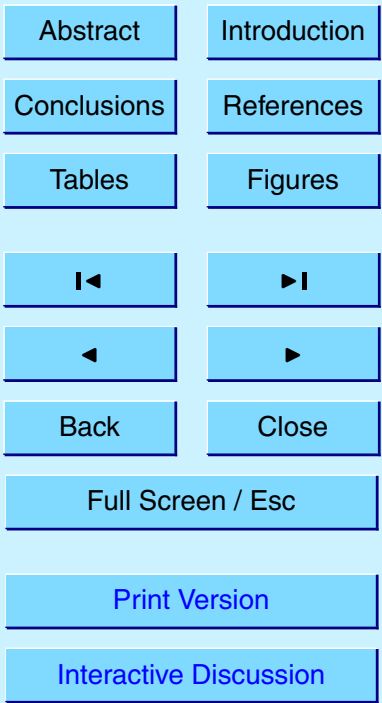

EGU 


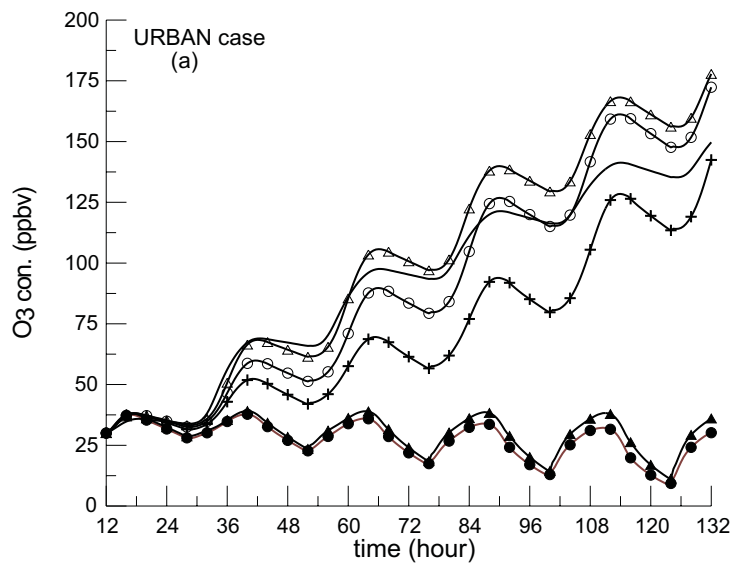

ACPD

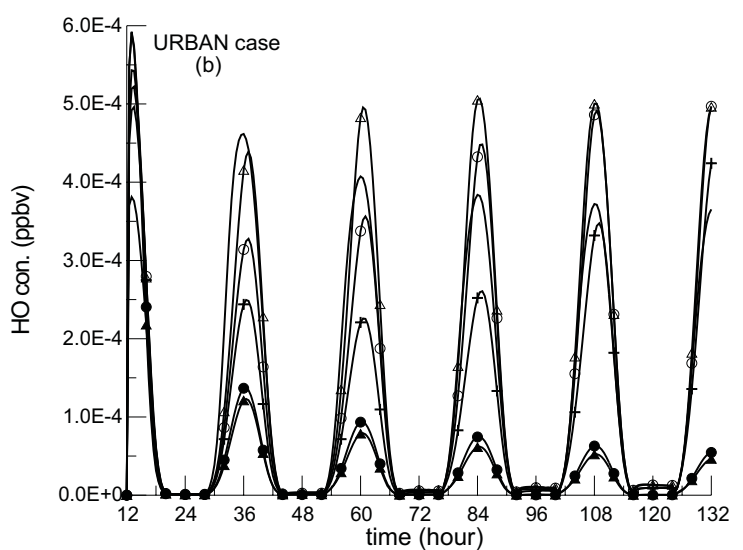

$5,6215-6262,2005$

Numerical integration of troposphere photochemistry mechanism

F. Liu et al.

\section{Title Page}

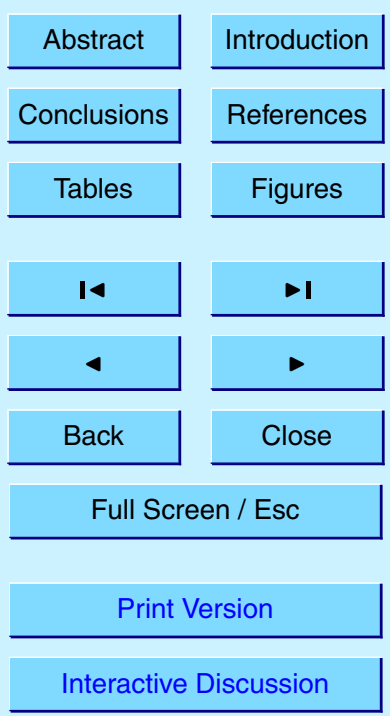
time for the URBAN case with different $N O$ emission strengths. The emissions are described in Table 3. The simulations start at noon with output every $30 \mathrm{~min}$. The $Q_{0}$ of $2.5900^{*} 10^{-3} \mathrm{ppb}$ Interactive Discussion $\mathrm{min}^{-1}$ is the base NO emission strength as prescribed in the PLUME case (Solid line: $Q_{0} ;-\triangle$ : $2.5 * Q_{0}$; -o-: $3.0 * Q_{0}$; -+-: $3.5 * Q_{0} ;-\bullet-: 5.0 * Q_{0} ;-\Delta-: 5.0 * Q_{0}$ with Mode A). 


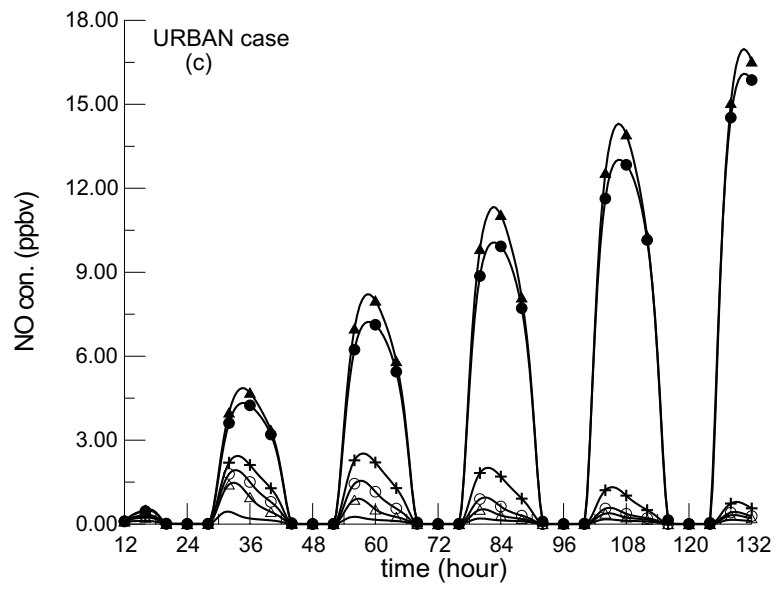

\section{ACPD}

5, 6215-6262, 2005

\section{Numerical integration of troposphere photochemistry mechanism}

F. Liu et al.
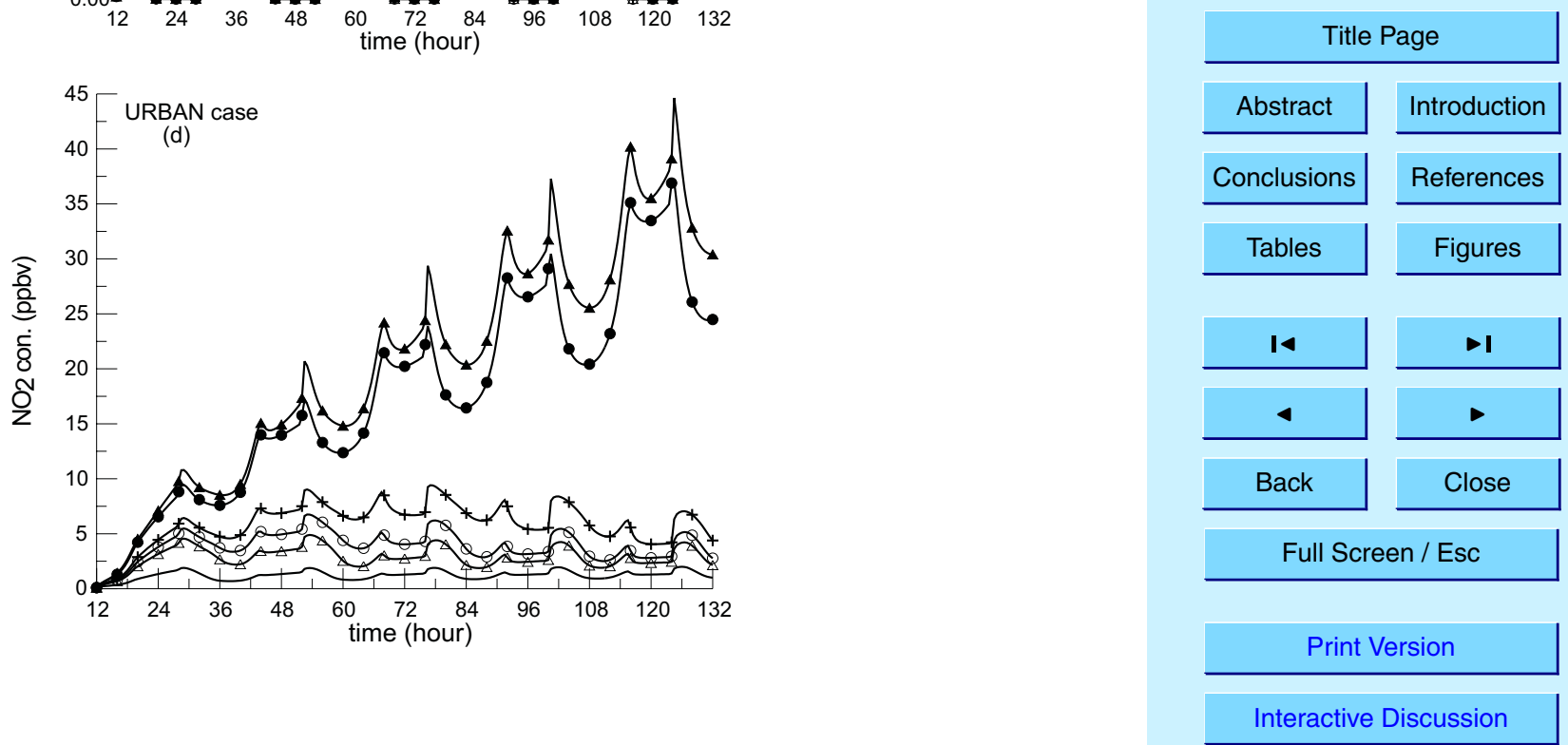

Fig. 5. Continued. 


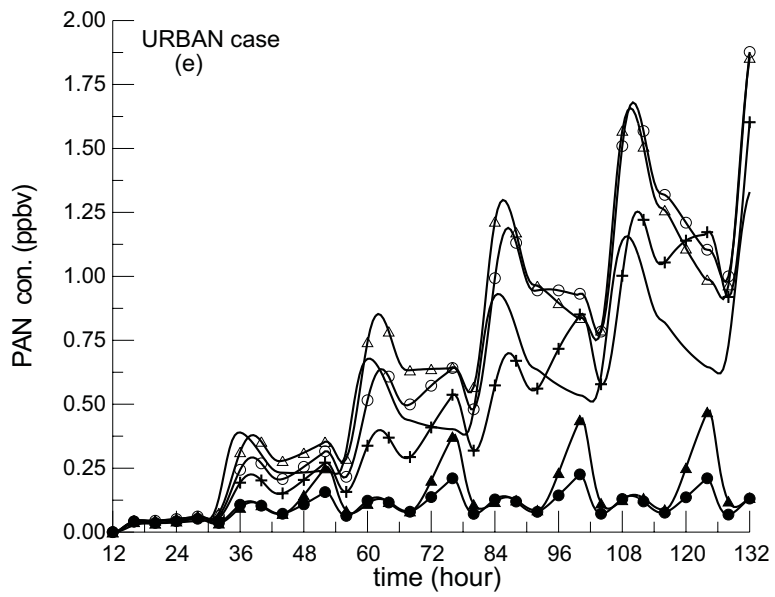

\section{ACPD}

5, 6215-6262, 2005

Numerical integration of troposphere photochemistry mechanism

F. Liu et al.

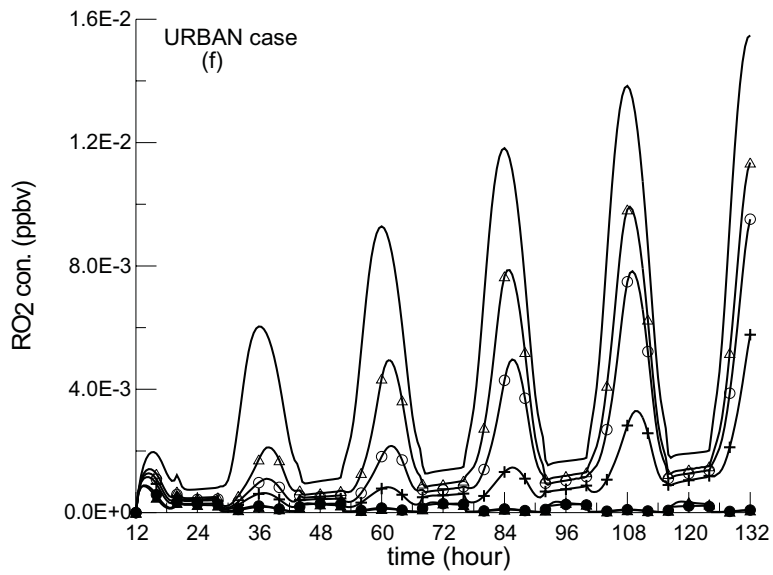

Title Page

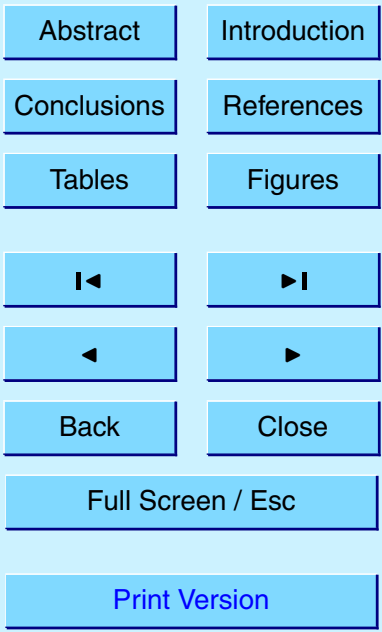

Interactive Discussion 


\section{ACPD}

$5,6215-6262,2005$

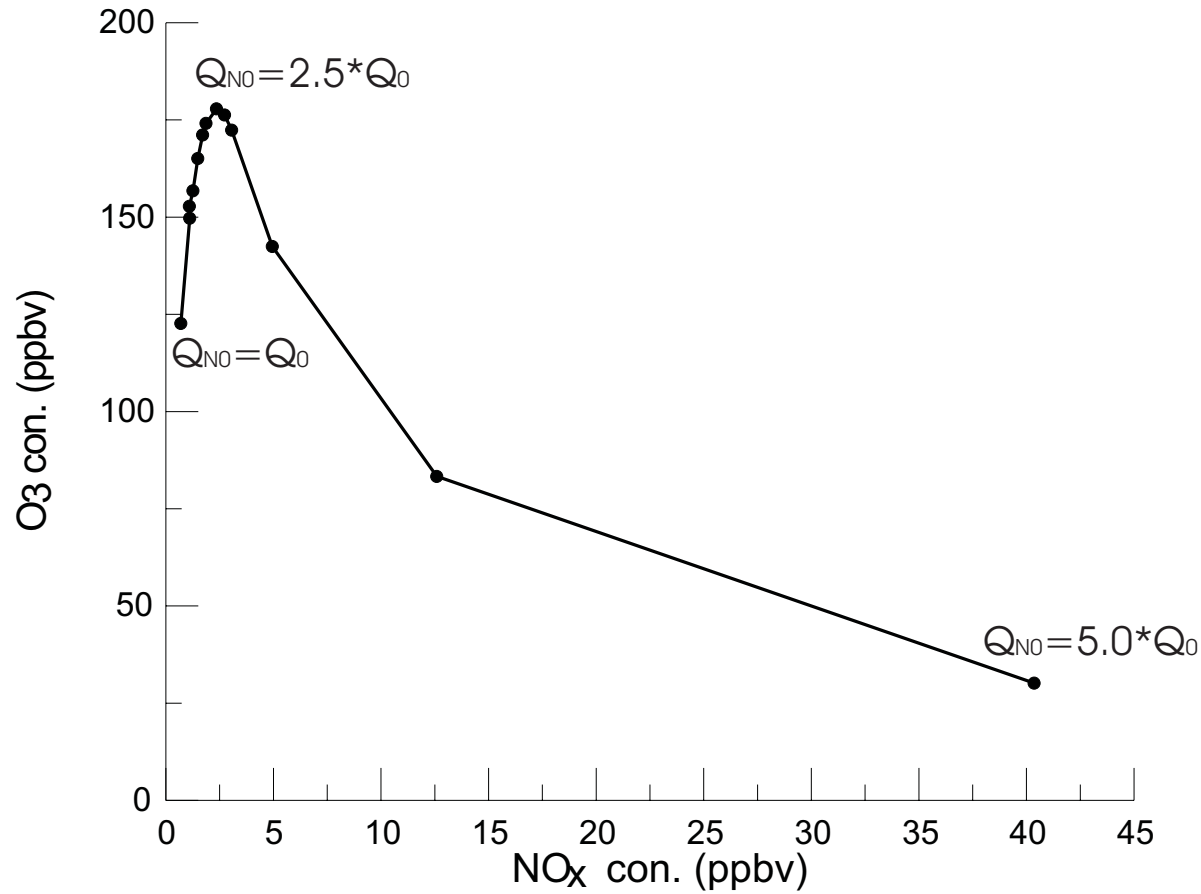

Numerical integration of troposphere photochemistry mechanism

F. Liu et al.

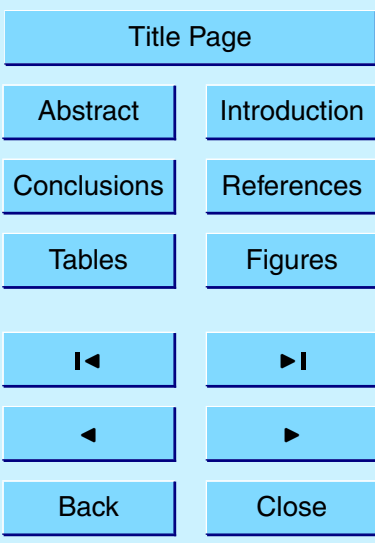

Fig. 6. $\mathrm{O}_{3}$ vs. $\mathrm{NO}_{\mathrm{x}}$ with different $\mathrm{NO}$ emission strengths after 5 days integration. The $Q_{N O}$ is the NO emission strength; the $Q_{0}$ is the value in the PLUME case as given in Fig. 5.

Full Screen / Esc

Print Version

Interactive Discussion 


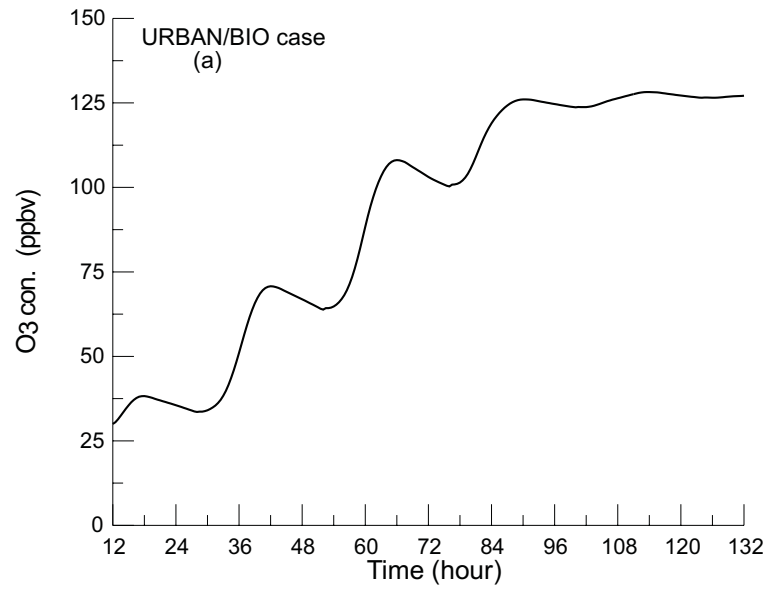

\section{ACPD}

$5,6215-6262,2005$

Numerical integration of troposphere photochemistry mechanism

F. Liu et al.
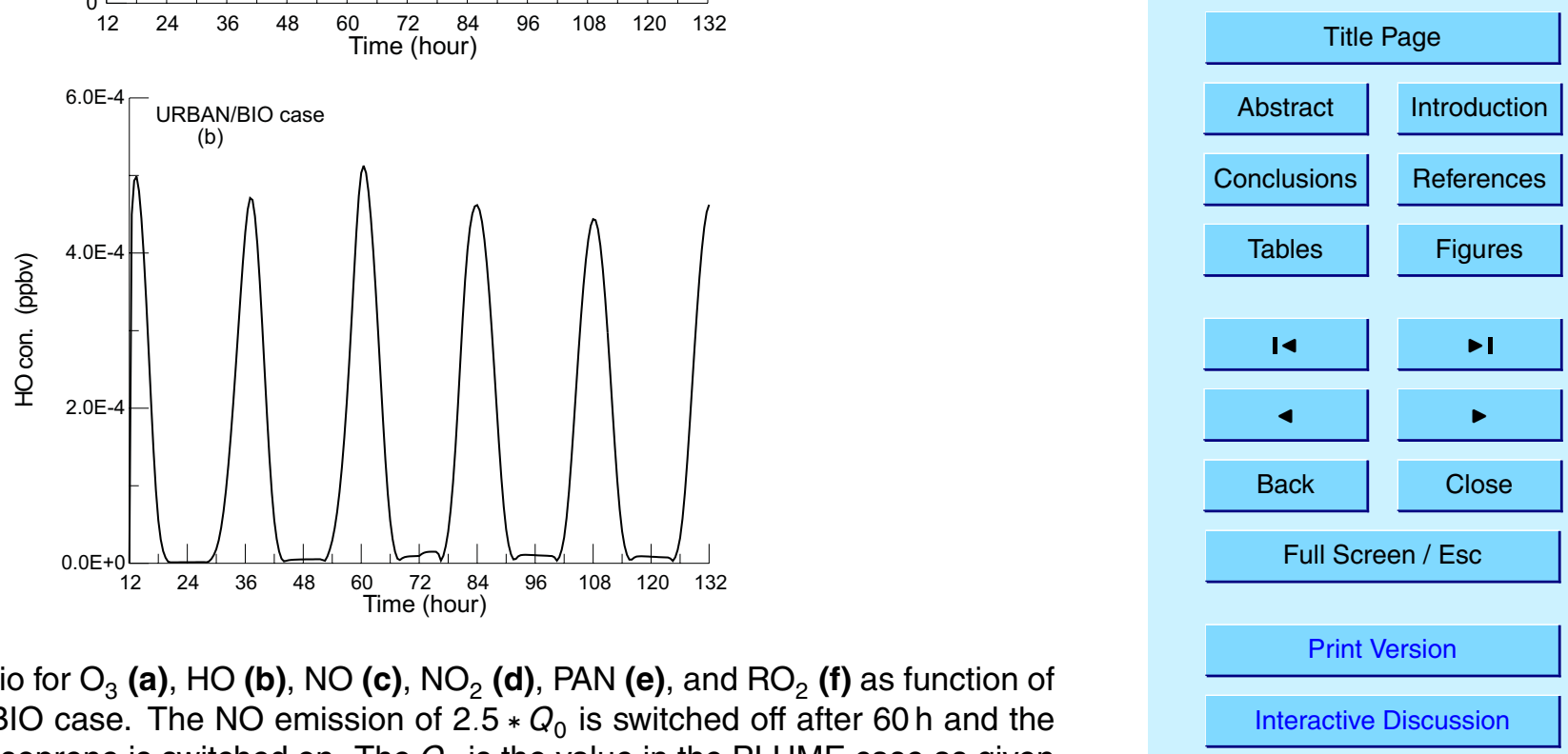

Fig. 7. The mixing ratio for $\mathrm{O}_{3}$ (a), $\mathrm{HO}(\mathbf{b}), \mathrm{NO}(\mathbf{c}), \mathrm{NO}_{2}$ (d), $\mathrm{PAN}(\mathbf{e})$, and $\mathrm{RO}_{2}$ (f) as function of time for the URBAN/BIO case. The NO emission of $2.5 * Q_{0}$ is switched off after $60 \mathrm{~h}$ and the biogenic emission of isoprene is switched on. The $Q_{0}$ is the value in the PLUME case as given Interactive Discussion in Fig. 5. The simulations start at noon with output every $30 \mathrm{~min}$. 


\section{ACPD}
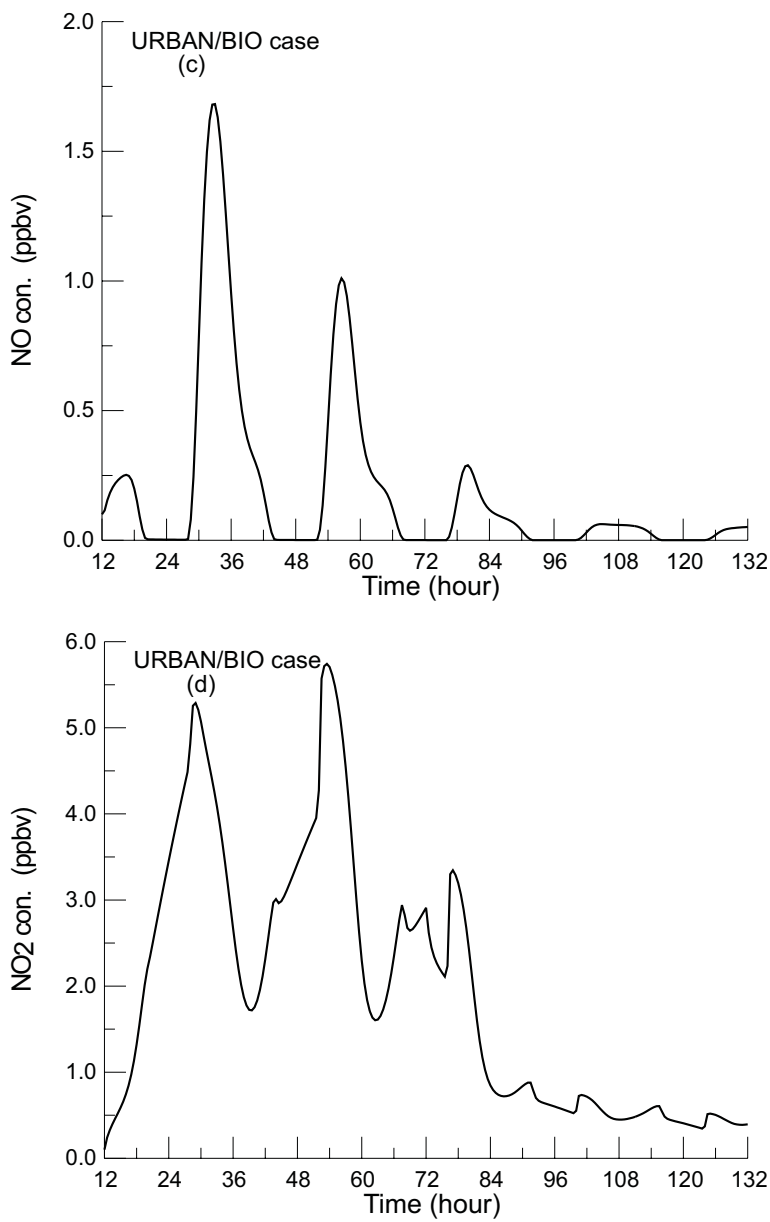

5, 6215-6262, 2005

Numerical integration of troposphere photochemistry mechanism

F. Liu et al.

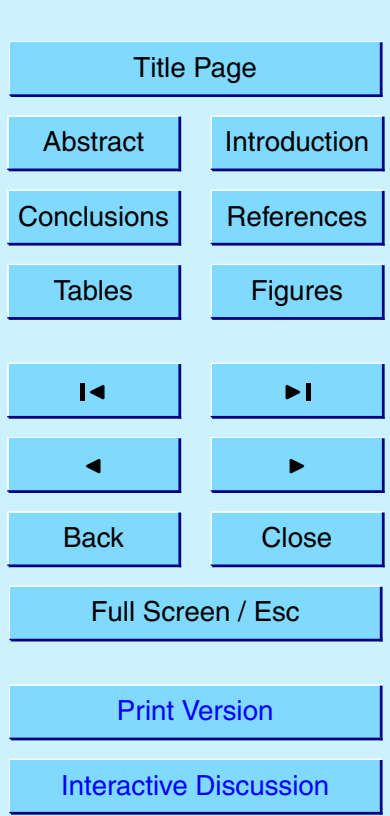

Fig. 7. Continued. 


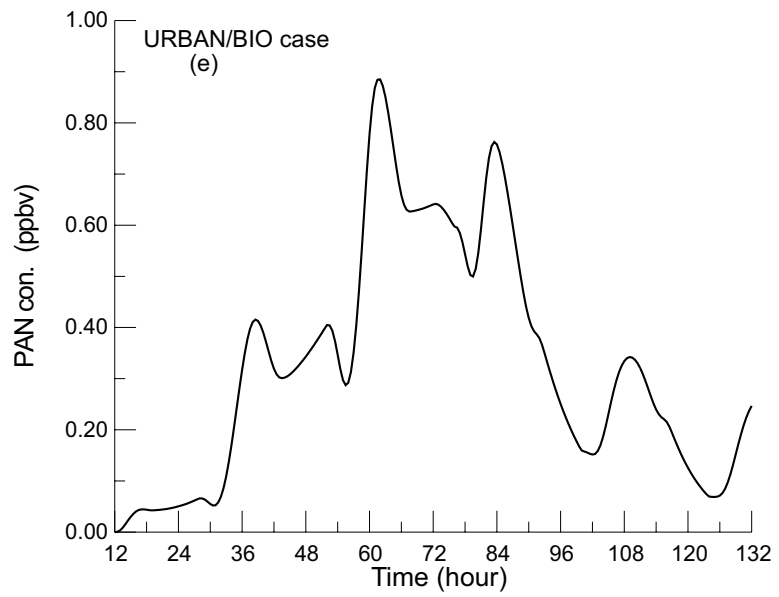

\section{ACPD}

5, 6215-6262, 2005

Numerical integration of troposphere photochemistry mechanism

F. Liu et al.

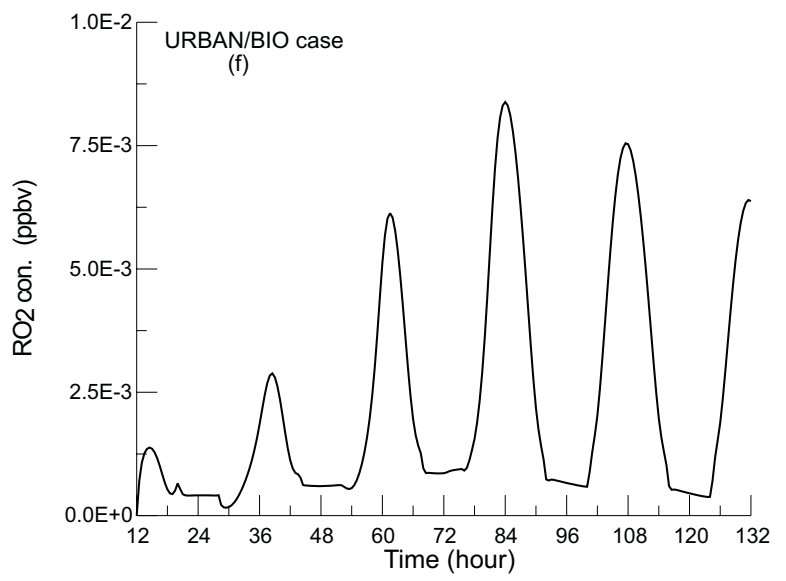

Title Page

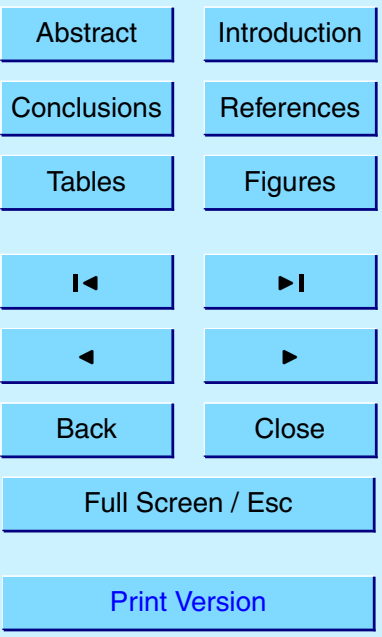

Interactive Discussion 


\section{ACPD}

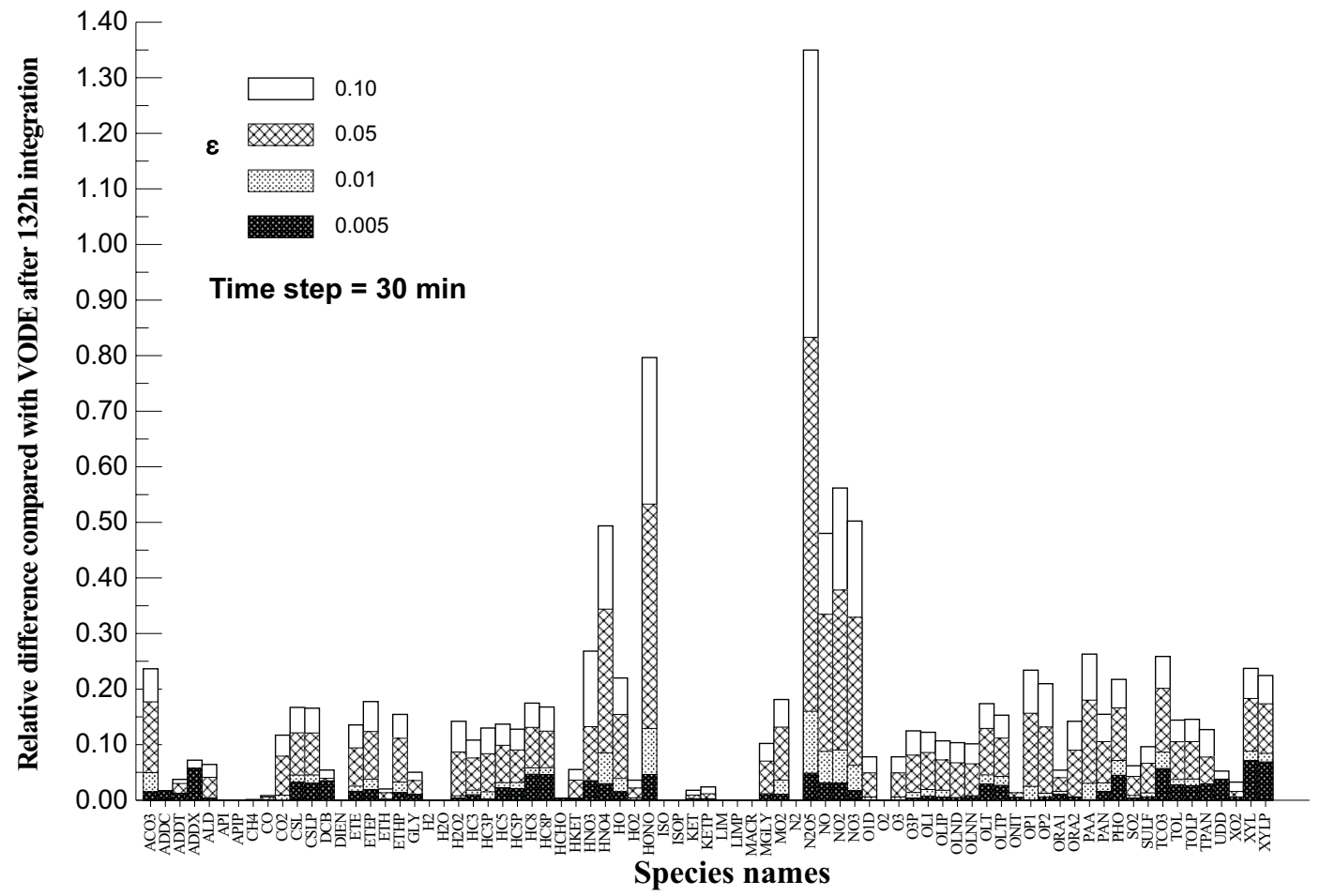

$5,6215-6262,2005$

Numerical integration of troposphere photochemistry mechanism

F. Liu et al.

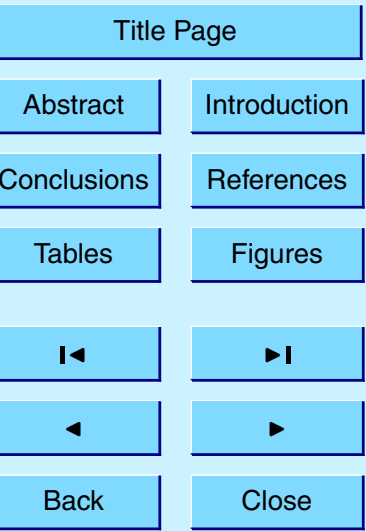

Fig. 8. The relative difference of mixing ratios compared with reference solutions for all species Full Screen / Esc at end integration for the PLUME case. The calculated root mean square $e_{r . m . s}$ for the four accuracy levels $\varepsilon$ 0.10, $0.05,0.01$ and 0.005 are $24.61 \%, 16.25 \%, 4.17 \%$ and $2.38 \%$, respectively.

Print Version

Interactive Discussion 


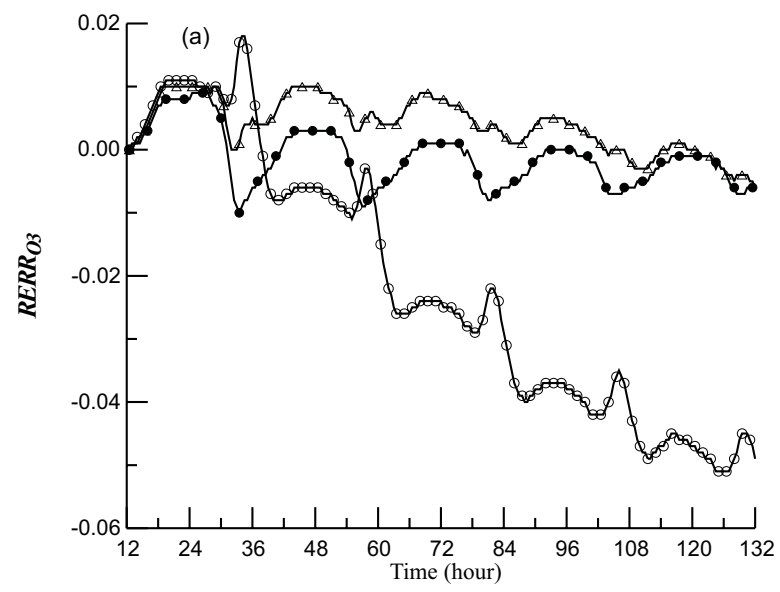

ACPD

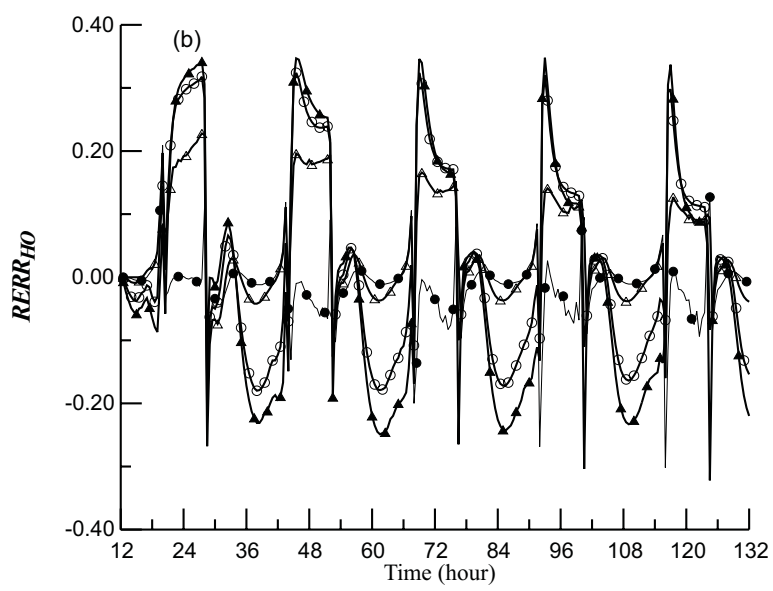

$5,6215-6262,2005$

Numerical integration of troposphere photochemistry mechanism

F. Liu et al.

Title Page

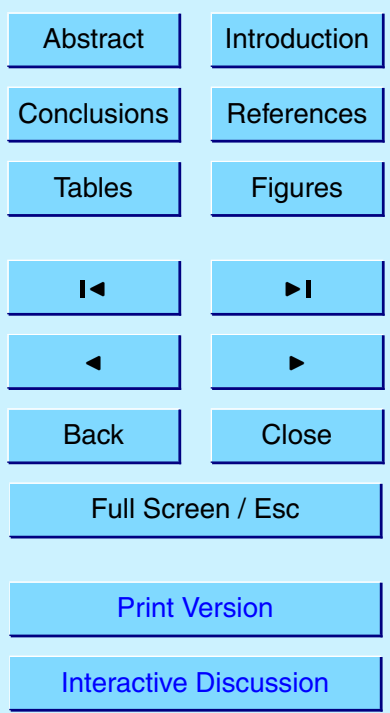

(g), and $\mathrm{RO}_{2}(\mathbf{h})$ as function of time for the PLUME case. The simulations start at noon with output every $30 \mathrm{~min}(-\Delta-: \varepsilon=0.10, N c=1 ;-0-: \varepsilon=0.05, N c=1 ;-\Delta-: \varepsilon=0.01, N c=1 ;-\bullet-: \varepsilon=0.005$, $N c=5)$. 


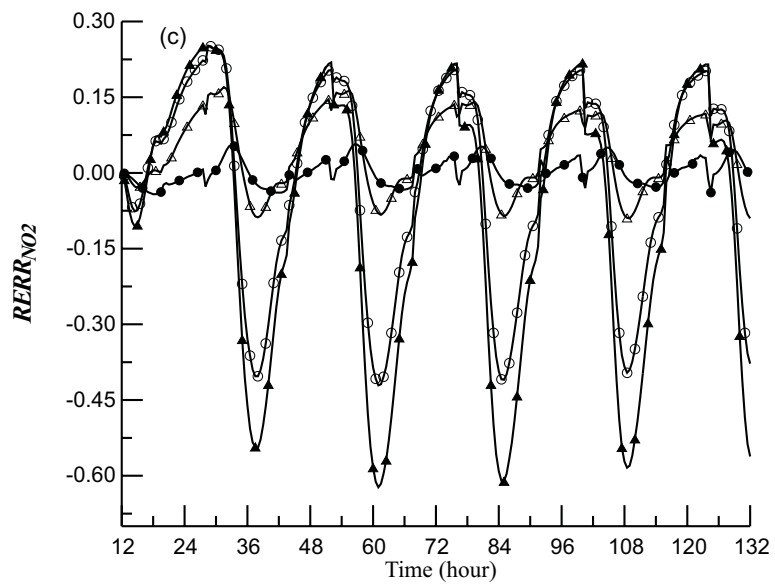

ACPD

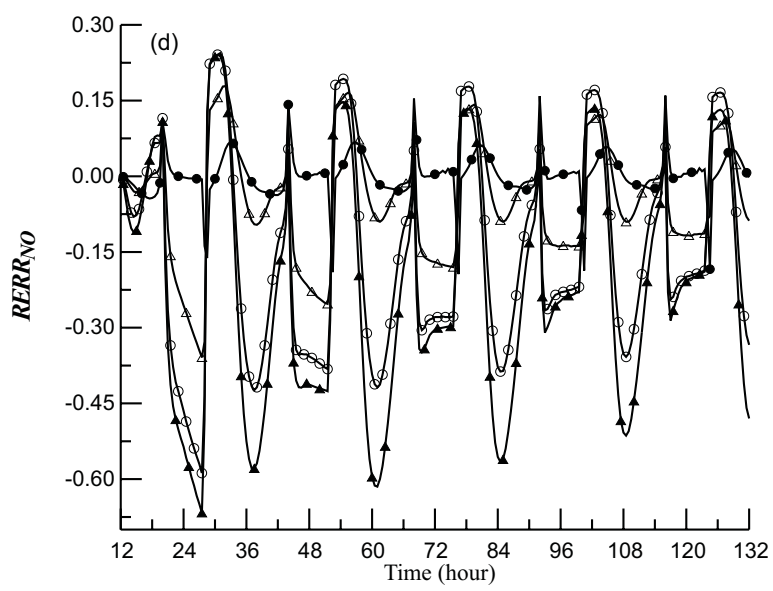

5, 6215-6262, 2005

Numerical integration of troposphere photochemistry mechanism

F. Liu et al.

Title Page

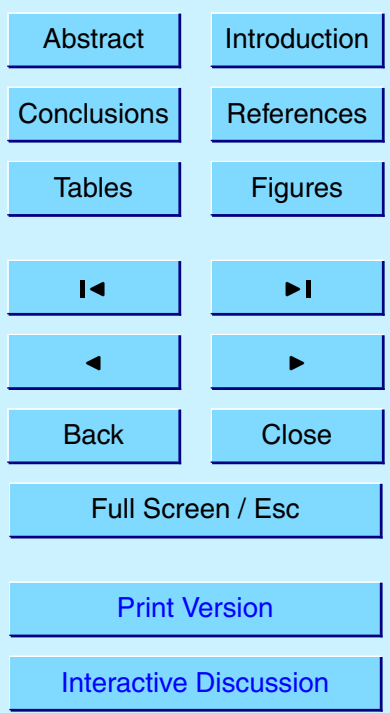

Fig. 9. Continued. 


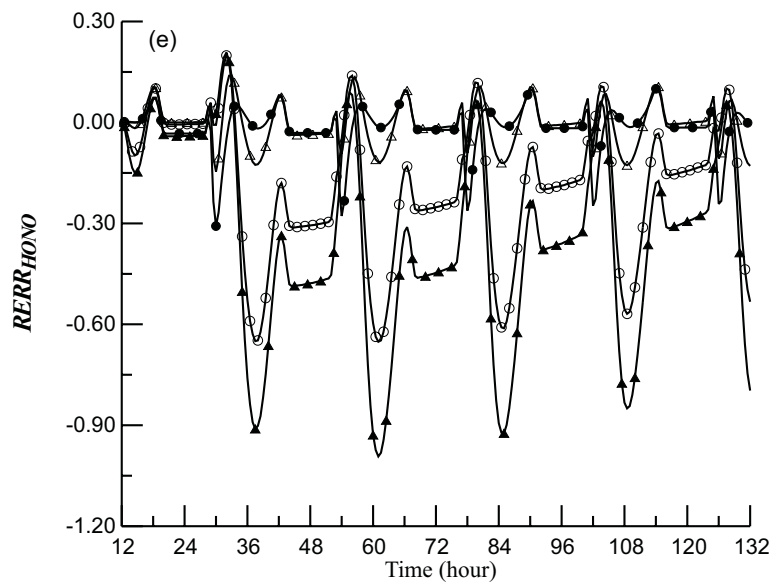

ACPD

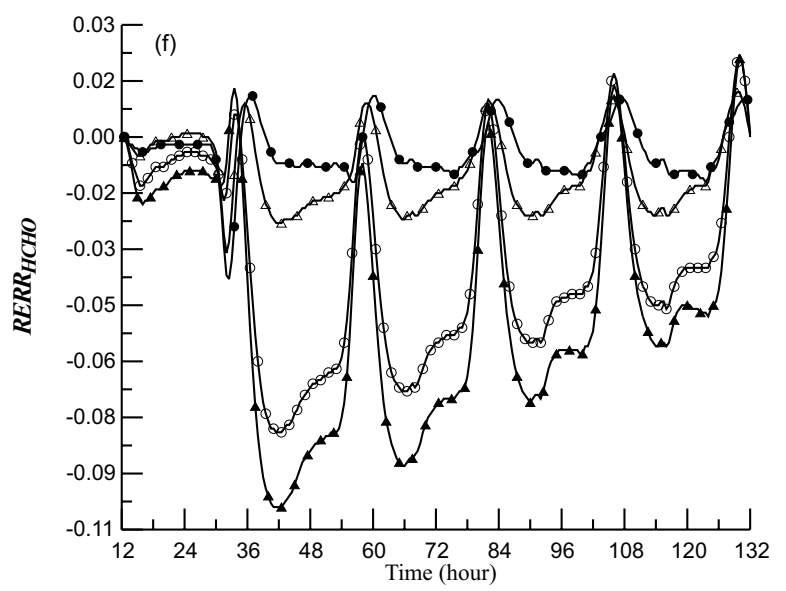

5, 6215-6262, 2005

Numerical integration of troposphere photochemistry mechanism

F. Liu et al.

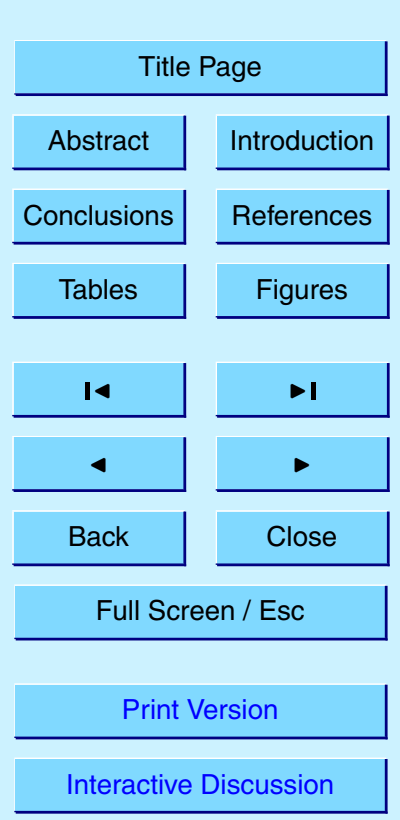




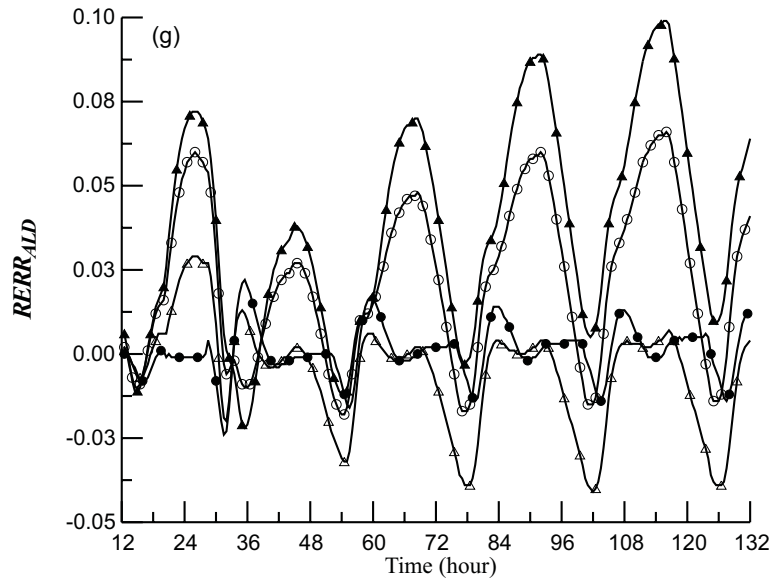

\section{ACPD}

5, 6215-6262, 2005

Numerical integration of troposphere photochemistry mechanism

F. Liu et al.

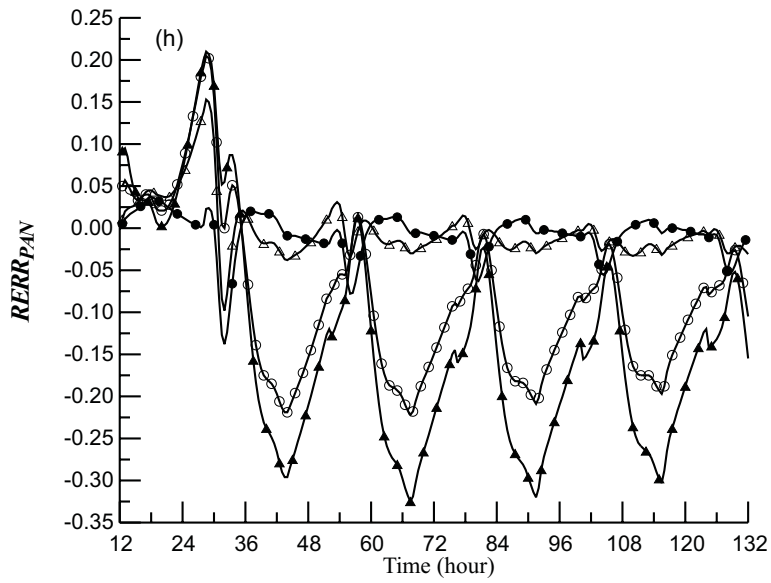

Title Page

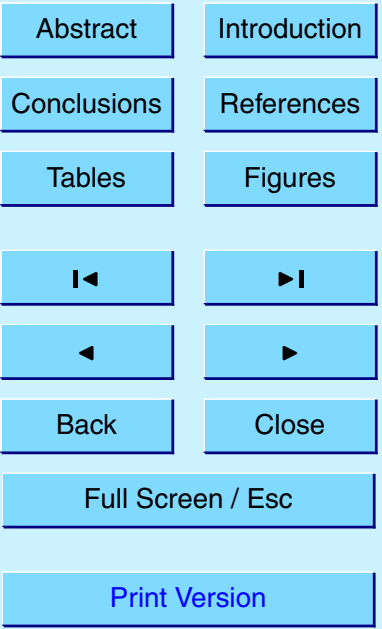

Fig. 9. Continued. 


\section{ACPD}

$5,6215-6262,2005$

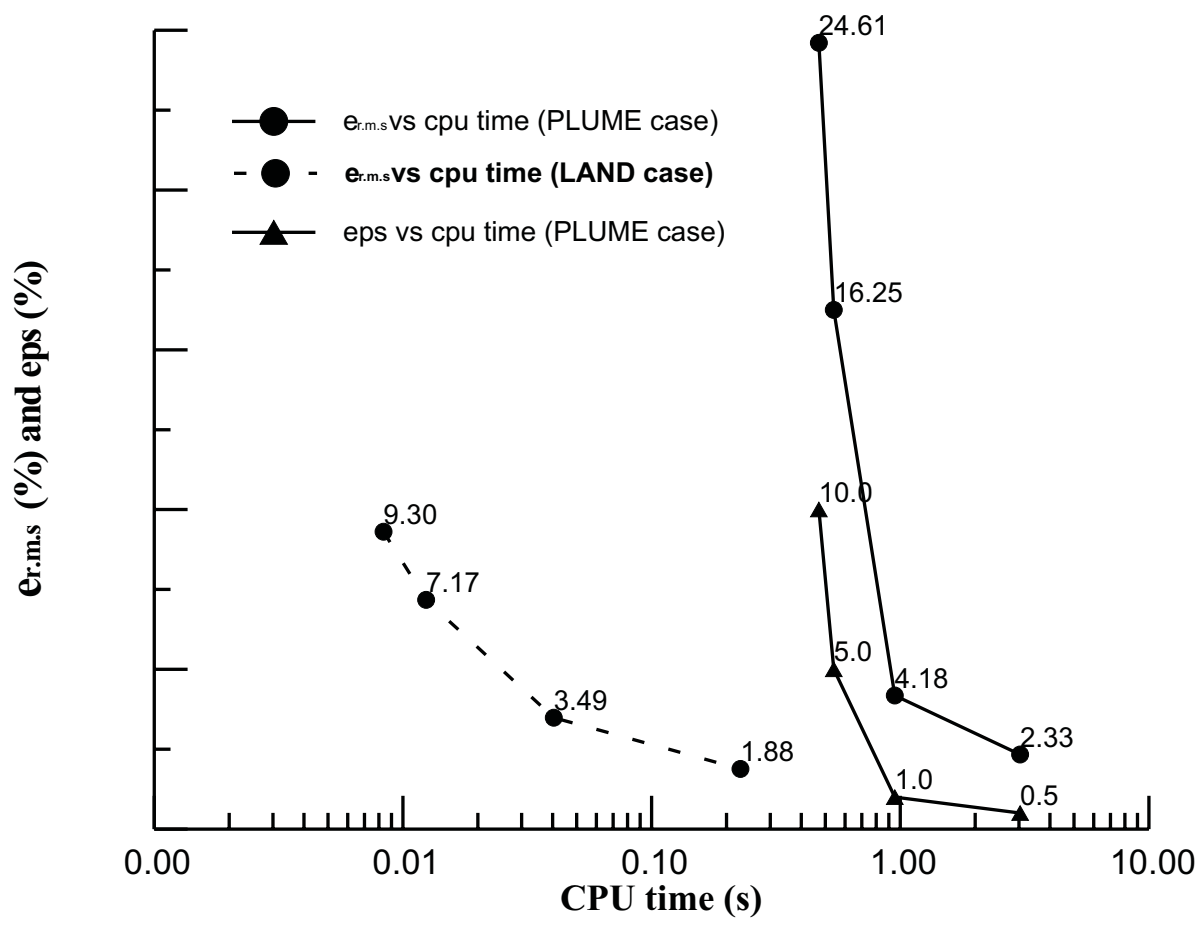

Numerical integration of troposphere photochemistry mechanism

F. Liu et al.

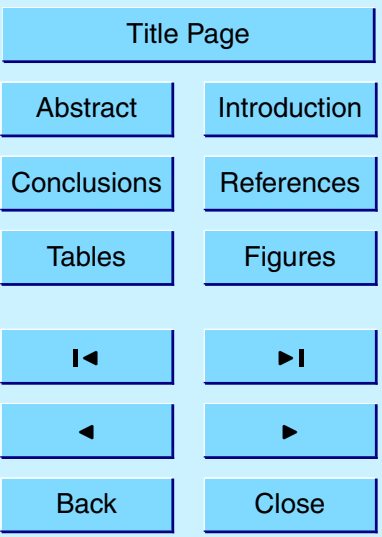

Fig. 10. Accuracy vs. CPU time. The $e_{r . m . s}$ is root mean square of relative difference for Full Screen / Esc all species in the RACM. The eps (\%) stands for predictor-corrector error tolerance $\varepsilon$ in the CHEMEQ2. (Solid line: the PLUME case and dashed line: the LAND case).

Print Version

Interactive Discussion 


\section{ACPD}

$5,6215-6262,2005$

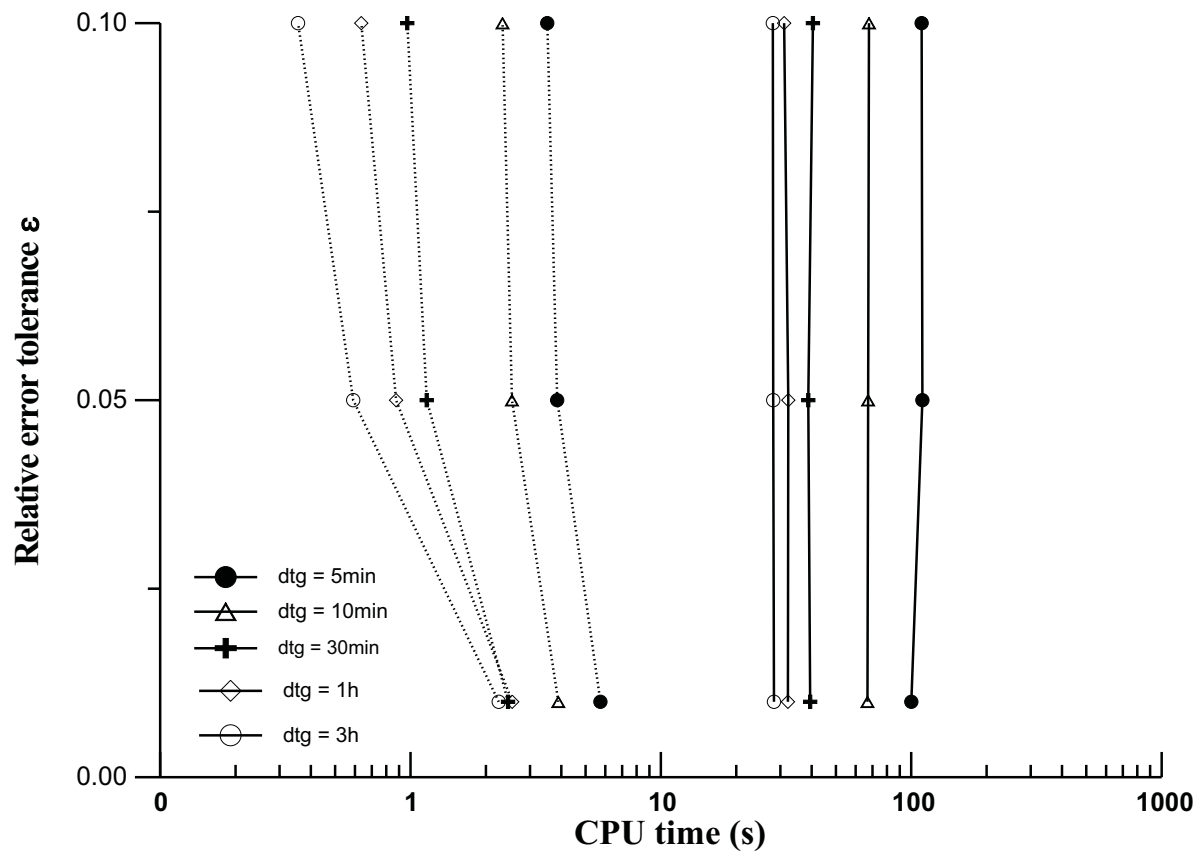

Numerical integration of troposphere photochemistry mechanism

F. Liu et al.

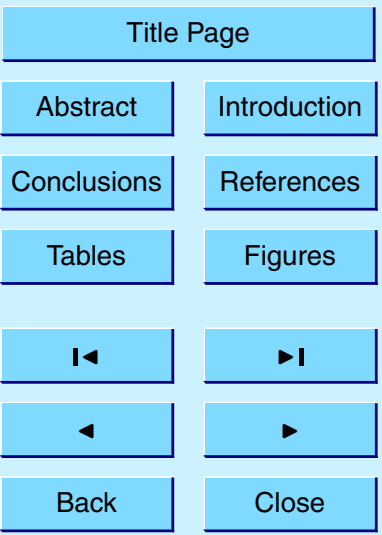

Fig. 11. Comparison of CPU time used by VODE and CHEMEQ2 solvers for 5 days simulations. The simulations are implemented with five scales of global time step ( $\Delta t_{g}=5 \mathrm{~min}, 10 \mathrm{~min}$, $30 \mathrm{~min}, 1 \mathrm{~h}$ and $3 \mathrm{~h}$ ) and three accuracy levels $(\varepsilon=0.10,0.05,0.01)$. (Solid line: VODE, dashed line: CHEMEQ2).

Full Screen / Esc

Print Version

Interactive Discussion 


\section{ACPD}

$5,6215-6262,2005$

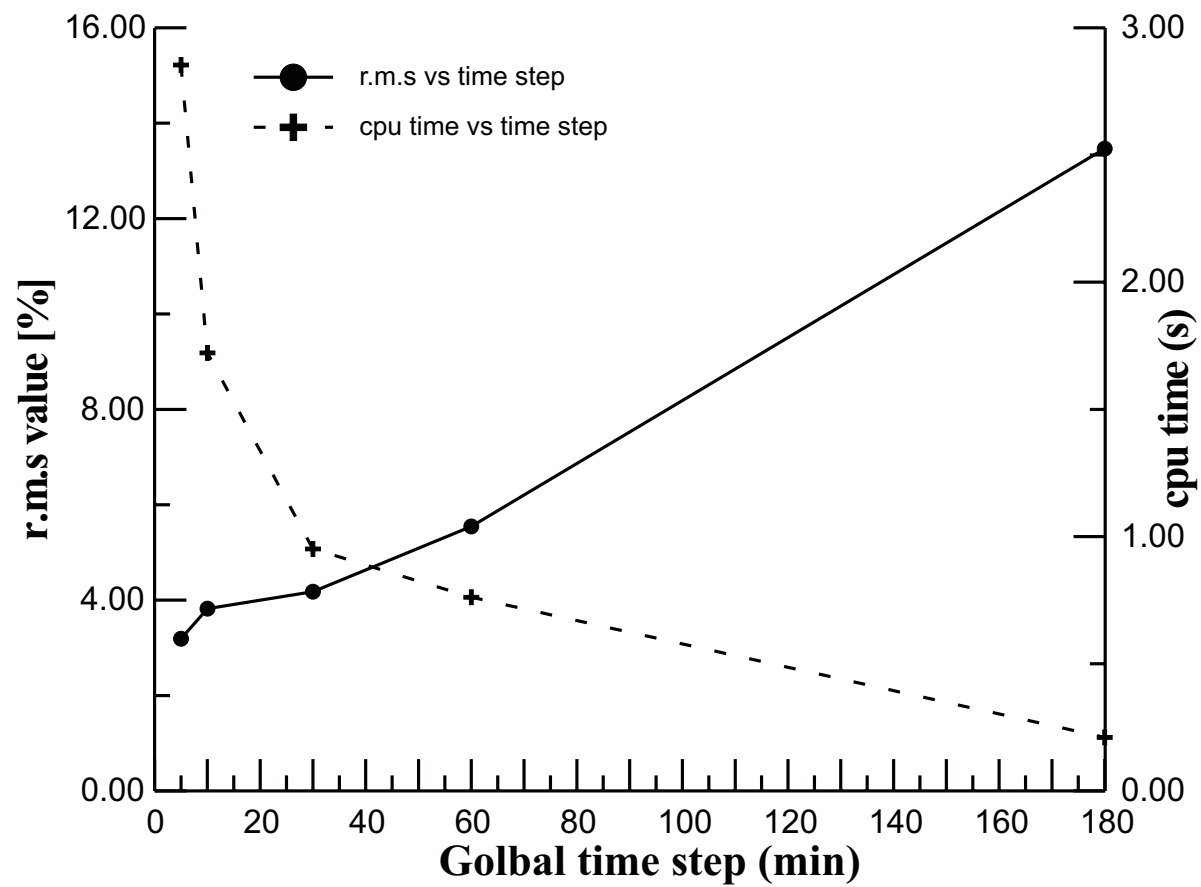

Numerical integration of troposphere photochemistry mechanism

F. Liu et al.

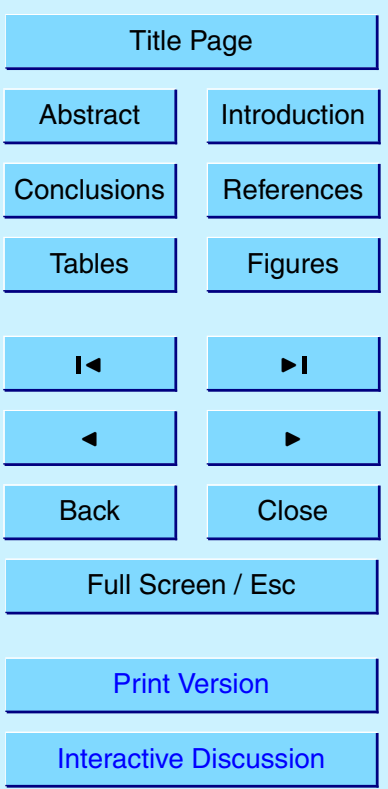

Fig. 12. The variations of r.m.s of relative difference and CPU time against global time step $\Delta t_{g}$. 